\title{
电子给体-受体型热活化延迟荧光蓝光材料研究进展
}

\author{
谭继华 $a$ 霍延平 $*, a, b$ 蔡 宁 ${ }^{a}$ 籍少敏 ${ }^{a}$ 李宗植 ${ }^{a}$ 张 力 $^{a}$ \\ ( ${ }^{a}$ 广东工业大学轻工化工学院 广州 510006) \\ ${ }^{b}$ 中国科学院上海有机化学研究所 有机氟化学中国科学院重点实验室 上海 200032)
}

\begin{abstract}
摘要 热活化延迟苂光材料由于其最低激发单重态和最低激发三重态之间的能级差较小, 三重态激子可以通过反向系 间窝越过程上转换到单重态, 实现无贵金属添加的三重态激子参与的苂光发射, 大大提高了发光效率, 解决了传统苂 光有机发光二极管 $(\mathrm{OLED})$ 内/外量子效率 $(\leqslant 25 \% / \leqslant 5 \%)$ 低下的问题; 与磷光 OLED 相比, 避免了使用贵金属, 在造价方 面具有更大优势. 在类型众多的热活化延迟苂光(TADF)材料中，由于电子给体-受体型分子合成简单，性能出众而成 为近年来的研究热点. 另一方面, 高效蓝光材料的稳定性及色纯度问题一直是该领域研究亟待解决的难题. 本文将依 据不同电子给受体单元, 对电子给体-受体型热活化延迟苂光蓝光材料及其 OLED 器件的最新进展、发光原理和设计原 则进行了简要综述, 并对其发展作出展望.
\end{abstract}

关键词Ｄ-A 型; 热活化延迟苂光; 蓝光材料; 有机发光二极管

\section{Progress on Donor-Acceptor Type Thermally Activated Delayed Fluorescence Based Blue Emitters}

\author{
Tan, Jihua ${ }^{a} \quad$ Huo, Yanping*,a,b \\ Cai, Ning ${ }^{a}$ \\ $\mathrm{Ji}$, Shaomin ${ }^{a}$ \\ Li, Zongzhi ${ }^{a}$ \\ Zhang, $\mathrm{Li}^{a}$
}

( ${ }^{a}$ School of Chemical Engineering and Light Industry, Guangdong University of Technology, Guangzhou 510006)

( ${ }^{b}$ Key Laboratory of Organofluorine Chemistry, Shanghai Institute of Organic Cheimstry, Chinese Academy of Sciences, Shanghai 200032)

\begin{abstract}
In thermally activated delayed fluorescence (TADF) based emitters, the excitons from the lowest triplet state ( $\mathrm{T}_{1}$ ) can be efficiently upconverted into the lowest singlet $\left(\mathrm{S}_{1}\right)$ state via reverse intersystem crossing (RISC) process due to the small energy gap $\left(\Delta E_{\mathrm{ST}}\right)$ between their $\mathrm{S}_{1}$ and $\mathrm{T}_{1}$ states, harvesting both $\mathrm{S}_{1}$ and $\mathrm{T}_{1}$ excitons for emission, with non-noble metals, which can break the internal/external quantum efficiency (IQE/EQE) $(\leqslant 25 \% / \leqslant 5 \%)$ limitation of conventional fluorescence based organic light-emitting diodes (OLEDs). Their no-noble metals feature makes them more competitive than phosphorescence materials in making OLEDs. Among the vast of TADF materials, eletrons donor-acceptor (D-A) type is one of the most popular TADF material due to their outstanding performance and convenience of preparation. On the other hand, efficient blue emitters are facing issues related to their stability and color purity that makes their development quite challenging for researchers. In this review, the D-A type blue TADF emitters and OLEDs reported recently are summarized, the mechanism of TADF based OLEDs and the principle of designs are elaborated, and a full vision of its development is made.

Keywords D-A type; thermally activated delayed fluorescence; blue emitter; organic light-emitting diode
\end{abstract}

1987 年, Tang 及 Van Slyke ${ }^{[1]}$ 首创性地报道了有机小 分子超薄多层电致发光二极管, 引发了学术界和工业领 域对有机发光二极管(OLED)的研发热潮. 由于 OLED 具有重量轻、柔软性好、工作温度范围宽、反应时间短、 亮度和对比度高及可视角宽等优点 ${ }^{[2]}$, 在平板显示、智
能手机以及固体发光等领域有着巨大的应用潜力. 一般 而言, OLED 主要由阳极、空穴传输层、发光层(由发光 材料单独组成或分散在主体材料中组成)、电子传输层 以及阴极依次堆叠组成, 空穴和电子分别由阳极和阴极 注入有机层, 在发光层相遇复合, 形成激子并发射出光

\footnotetext{
* Corresponding author. E-mail: organicteacherhuo@126.com

Received April 11, 2017; revised June 3, 2017; published online June 16, 2017.
}

Project supported by the National Natural Science Foundation of China (Nos. 61671162, 21372051), the Science and Technology Planning Project of Guangdong Province (No. 2016A010103031) and the Guangdong Provience Universities and Colleges Young Pearl River Scholar Funded Scheme (2016).

国家自然科学基金(Nos. 61671162, 21372051)、广东省科技计划(No. 2016A010103031)及广东省高等学校青年珠江学者岗位计划(2016)资助项目. 
子, 这一现象最开始在葱单晶中被观察到 ${ }^{[3]}$. 激子从激 发态到基态的辐射失活过程中存在不同的自旋多重态, 例如单重态或三重态，从而发射不同性质的光，即苂光 或磷光. 相应的, 基于电子从最低激发单重态 $\left(\mathrm{S}_{1}\right)$ 辐射 失活回到基态发光原理的器件为传统荧光 OLED; 以电 子从最低激发三重态 $\left(\mathrm{T}_{1}\right)$ 辐射跃迁到基态发光原理的器 件为磷光 OLED. 根据自旋统计定理 ${ }^{[4]}$, 电激发电子按 $1: 3$ 的比例分别产生单重态和三重态激子(即分别占 $25 \%$ 和 $75 \%$ ), 而量子力学理论的选择规则 ${ }^{[5]}$ 指出, 只有 当两个电子态具有相同自旋多重性时才能实现相互转 换, 而具有不同自旋多重性的两个电子态之间的跃迁是 被禁阻的，一般情况下，基态为自旋单重态 $\left(\mathrm{S}_{0}\right)$. 因此， 不难发现, 传统荧光 OLED仅仅利用 $25 \%$ 的 $\mathrm{S}_{1}$ 态电致激 子发光, $75 \%$ 的 $\mathrm{T}_{1}$ 态电致激子由于自旋禁阻作用以非辐 射失活的形式回到 $\mathrm{S}_{0}$ 态导致热散失从而造成 “浪费”. 因此, 传统苂光 OLED 的内量子效率(internal quantum efficiency, IQE)仅有 $25 \%$, 而遵循朗伯发光模式的荧光 OLED 器件的光取出效率只有 $20 \%$ 左右, 所以传统荧光 OLED 器件的最大外量子效率 (external quantum efficiency, EQE) 只有 5\%. 另一方面, 传统纯有机发光分子 由于 $\mathrm{S}_{1}$ 态和 $\mathrm{T}_{1}$ 态之间自旋多重性不一致而造成的跃迁 禁阻, 使得两者之间普遍存在较大的 $\Delta E_{\mathrm{ST}}(>0.5 \mathrm{eV})$. 故一般情况下, 传统纯有机小分子仅发射荧光, 不发射 磷光. 直到 1998 年, Baldo 等 ${ }^{[6]}$ 首次报道通过在有机小分 子中引入铱(III)、铂(II)以及锇(II)等金属形成配合物, 可 以通过自旋偶合作用加强分子内部系间窝越 (intersystem crossing, ISC), 从而实现了在室温下 $\mathrm{S}_{1}$ 和 $\mathrm{T}_{1}$ 共同参与的磷光发射, 获得了理论上达到 $100 \%$ 的 IQE，以朗伯模式发光获得 $20 \%$ 的最大 $\mathrm{EQE}$, 克服了传 统荧光 OLED 器件发光效率低下的问题. 尽管如此, 磷 光 OLED 器件在高电流密度工作状态下, 三重态-三重 态湮灭效应尤为显著, 导致器件有机层之间的激子扩散 猝灭, 造成显著的器件效率滚降效应, 通常需要掺杂在 相应的主体材料中，以获得更好的效率稳定性 ${ }^{[7]}$. 同时， 由于磷光材料掺杂了稀土金属等贵金属, 导致其合成成 本居高不下, 不利于大规模生产.

众所周知, 全彩显示或固态发光均需要红色、绿色 和蓝色 (red, green and blue, RGB)三种基本色光. 图 1 为 1931 年由国际照明委员会(Commission Internationale de I'Eclairage, CIE)发布的色品图. 当发光材料的发射光谱 的 CIE 色坐标落在色品图左下角蓝色区域时, 即可称之 为蓝光材料. 后来, 考虑到全彩显示和固态发光技术, 美国电视委员会(US National Television Systems Committee, NTSC)和欧洲广播联盟(European Broadcasting Union, EBU)分别对标准蓝光作出了定义. 其中 NTSC
将标准蓝光材料的 CIE 坐标值限定为 $x+y<0.30$, 深蓝 光材料的 CIE 坐标 $y<0.08$; 而 EBU 则规定深蓝光材料 发射光谱的 CIE 坐标 $y<0.06^{[8]}$. 因此, 获得深蓝光材料 意味着材料需要具有一个十分宽的 HOMO, LUMO 能隙 $\left(E_{\mathrm{g}}\right)(>3.0 \mathrm{eV})$, 而宽能隙必然会对材料分子的设计造 成困扰, 其 OLED 器件也会使空穴和电子注入有机层变 得十分困难. 同时, 相较于绿光和红光材料, 蓝光材料 通常表现出更差的电致发光性能: 较低的器件效率, 更 短的器件寿命以及差的色纯度 ${ }^{[8]}$. 因此, 性能优异的全 彩显示或固态发光材料不但需要高电致发光效率及长 器件寿命, 还需要具有适当的发光波长, 以表现出 RGB 基础色光. 合成 CIE 色坐标 $(0.10,<0.10)$, 发光寿命 $>$ $10000 \mathrm{~h}$ 以及高发光效率的蓝光材料, 对于全彩显示和 固态发光技术的进一步发展具有十分重要的意义.

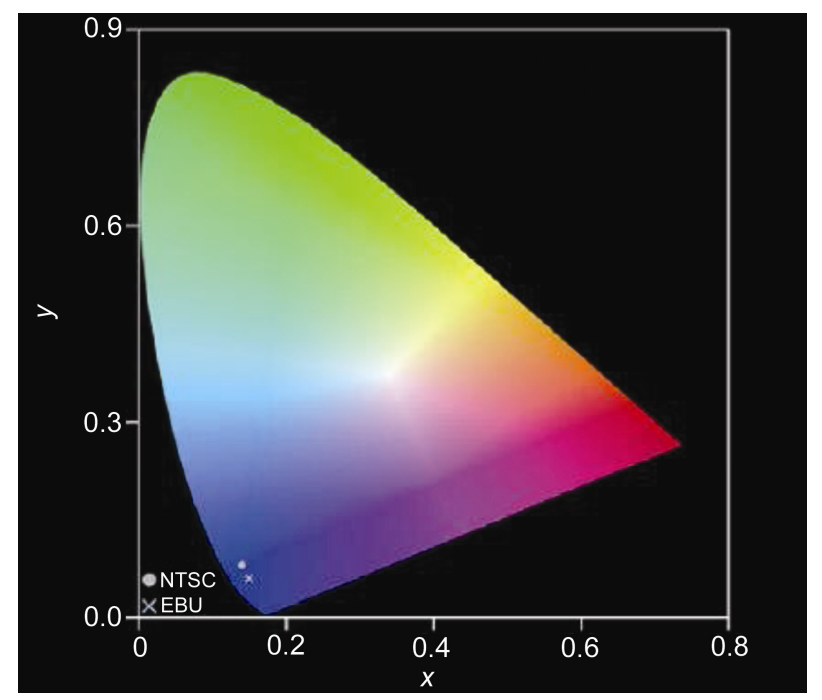

图 1 CIE 色品图以及 NTSC 和 EBU 定义的标准蓝光坐标 Figure 1 CIE chromaticity diagram and the position of NTSC \& EBU's standard blue emitters

综上所述，研发具有高性价比的蓝光材料已经成为 推动有机光电器件进一步发展的当务之急. 近年来, Adachi 团队 ${ }^{[9]}$ 报道了一种以热活化延迟苂光(thermally activated delayed fluorescence, TADF)作为发光机理的全 新 OLED 器件. 该类器件可在不引入贵金属或稀土金属 的情况下实现 $\mathrm{S}_{1}$ 态和 $\mathrm{T}_{1}$ 态激子共同参与苂光发射. 其 IQE 理论值可达到 $100 \%$, 可謧美磷光 OLED, 并且在合 成成本上比磷光 OLED 具有更大的优势, 被誉为 “第三 代” 发光器件. 如图 2 所示, 分子的 $\mathrm{S}_{1}$ 态在能量上高于 $\mathrm{T}_{1}$ 态, 两者之间存在一定的能级差 $\left(\Delta E_{\mathrm{ST}}\right)$, 当 $\Delta E_{\mathrm{ST}}$ 足够 小 $(<0.5 \mathrm{eV})$ 时, 分子内部发生反向系间窝越(reverse intersystem crossing, RISC): $\mathrm{T}_{1}$ 态激子通过吸收环境热上 转换到 $\mathrm{S}_{1}$ 态 ${ }^{[10 ~ 12]}$. 原本占据在 $\mathrm{S}_{1}$ 态的 $25 \%$ 的激子迅速 辐射失活产生纳秒级的即时荧光 (prompt fluorescence, 
$\mathrm{PF}), 75 \%$ 的 $\mathrm{T}_{1}$ 态激子通过 RISC 过程上转换到 $\mathrm{S}_{1}$ 态后辐 射失活产生微秒级甚至毫秒级寿命的延迟苂光(delayed fluorescence, DF), 由于两者在发光光谱上完全一致, 二 者构成的 TADF 比传统荧光在寿命上高出 3 个数量级. 根据玻耳兹曼分布关系, RISC 速率常数 $k_{\mathrm{RISC}}$ 与 $\Delta E_{\mathrm{ST}}$ 成 正比:

$$
k_{\mathrm{RISC}} \propto \exp \frac{\Delta E_{\mathrm{ST}}}{k_{\mathrm{B}} T}
$$

$k_{\mathrm{B}}$ 为玻耳兹曼常数, $T$ 为温度. 所以, 为了实现高效的 $\mathrm{TADF}$, 获得分子内足够小的 $\Delta E_{\mathrm{ST}}$ 至关重要. Tao 等 ${ }^{[13]}$ 的研究指出, $\Delta E_{\mathrm{ST}}$ 满足下列关系式:

$$
\begin{aligned}
& E_{\mathrm{S}}=E+K+J \\
& E_{\mathrm{T}}=E+K-J \\
& \Delta E_{\mathrm{ST}}=E_{\mathrm{S}}-E_{\mathrm{T}}=2 J
\end{aligned}
$$

其中 $E$ 为轨道能量, $K$ 为电子排斥能, $J$ 为交换能. 根据 量子理论, 交换能 $J$ 与分子的 HOMO 和 LUMO 能级及 空间波函数有关. 一般而言, 电子给体-电子受体 (eletron donor-acceptor, D-A)分子通过基团之间空间阻 碍作用使电子给、受体产生空间扭转, 可以使 HOMO 和 LUMO 能级分别分布在电子给体和电子受体上, 从

(a)
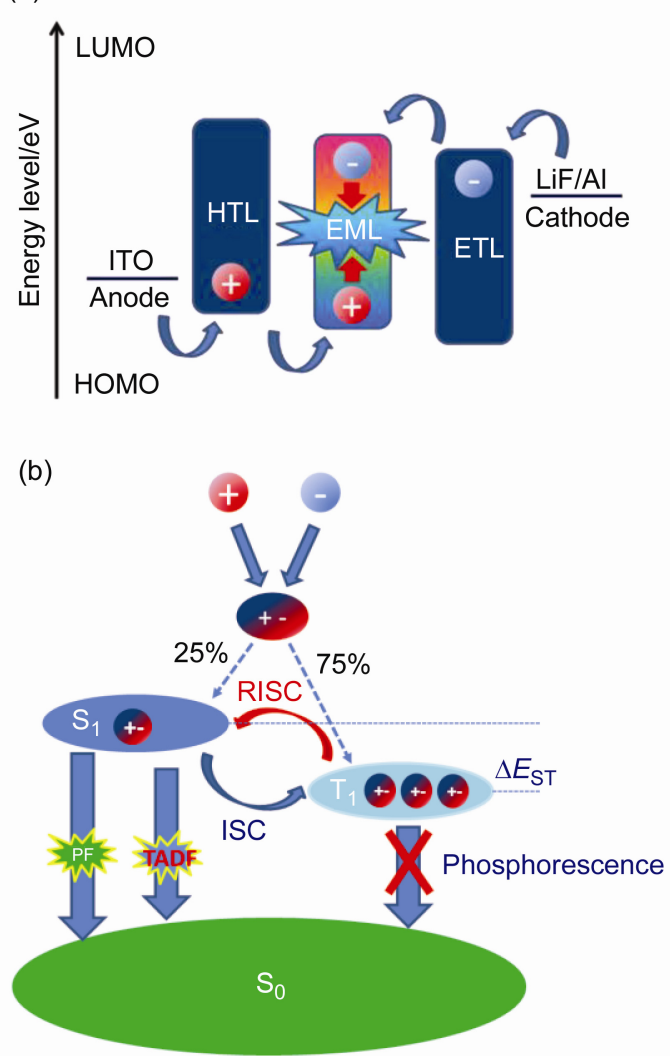

图 $2 \mathrm{TADF}$ 能级图(a)及机理图(b)

Figure 2 TADF energy level (a) and mechanism (b) diagram
而很大程度上实现分子的 HOMO 和 LUMO 能级在空间 上分离，使分子 $\Delta E_{\mathrm{ST}}$ 降低. 所以，高效的 TADF 是基于 足够小的 $\Delta E_{\mathrm{ST}}$ 和相对较大的 $k_{\mathrm{r}}$ 实现的.

\section{D-A 型热活化延迟荧光蓝光材料的设计及其 合成策略}

尽管 TADF 现象独特, 机理复杂, 但 TADF 材料的 设计却有一定的规律可循. 就高效的 D-A 型 TADF 蓝光 材料而言，应该同时满足下列三个条件: (1)相对小的 $\mathrm{S}_{1}$ 态和 $\mathrm{T}_{1}$ 态能级差 $\left(\Delta E_{\mathrm{ST}}\right)$ 以实现高效的 RISC 过程; (2)相 对大的 $\mathrm{S}_{1}$ 态辐射衰减率 $\left(k_{\mathrm{r}}\right)$ 以获得较高的苂光量子产率 (photoluminescence quantum yield, PLQY); (3) $\mathrm{S}_{1}$ 能级需 $\geqslant 2.9 \mathrm{eV}$ 以实现纯蓝光发射. 其中小的 $\Delta E_{\mathrm{ST}}$ 可以通过 分离的 HOMO 和 LUMO 能级来实现 ${ }^{[14]}$. 根据给体单元 决定 HOMO 分布、受体单元决定 LUMO 分布的基本规 律, D-A 结构可方便地调控 HOMO 和 LUMO 分离和重 叠程度. 具体地, 可以通过下列方法实现 D-A 分子 HOMO 和 LUMO 能级的分离(图 3): (a)通过巧妙选择电 子给、受体或添加修饰基团以引起较大的空间位阻 ${ }^{[15]}$; (b) 通过螺连接 ${ }^{[16]}$ 、正交连接 ${ }^{[17]}$ 等特殊键接方式或通过 物理方式实现电子给体和电子受体的空间分离; (c)通过 “蝴蝶构型” ${ }^{[18]}$ 、“ $X$ 型构型” ${ }^{[19]}$ 等特殊分子构型实现 HOMO 和 LUMO 能级分离; 此外, 还有(d)通过构建刚 性平面并引入具有相反共振效应的原子以获得多重共 振效应的方式获得较小 $\Delta E_{\mathrm{ST}}{ }^{[20]}$.

另一方面, 根据 Franck-Condon 理论 ${ }^{[21]}$, HOMO 和 LUMO 一定的重叠是实现高 PLQY 的必要条件, 显然高 $\mathrm{PLQY}$ 与低 $\Delta E_{\mathrm{ST}}$ 之间理论上是相矛盾的, 所以在设计高 效的 D-A 型 TADF 材料时需要巧妙选择电子给体与受 体, 平衡考虑 $\Delta E_{\mathrm{ST}}$ 与 PLQY 两个因素是获得高效 TADF 材料的前提条件. 目前获得高 PLQY 的途径有如下几 点：通过分子内电子给体、电子受体基团的密集连接以 及加强分子结构的刚性, 可以降低分子的重组能, 从而 减少非辐射衰变, 以获得较高的辐射衰变速率 ${ }^{[22]}$; 增加 分子基态的电子波函数重叠密度分布，可以提高 $\mathrm{S}_{1}$ 态 到基态的辐射衰变速率，以达到增加 PLQY 的效果 ${ }^{[23]}$; HOMO 和 LUMO 能级的有效分离可以使分子前线轨道 产生离域，从而在保证获得小的 $\Delta E_{\mathrm{ST}}$ 同时，抑制辐射衰 减速率的降低 ${ }^{[24]}$; 通过巧妙引入修饰官能团, 使 TADF 分子获得聚集诱导效应，可以较少 TADF 分子浓度淬灭 和激子湮灭，进而提高辐射衰减速率，获得更高的 $\mathrm{PLQY}^{[22]}$. 同时, 为了获得深蓝色的 TADF 材料, 必须合 理搭配电子给体和电子受体, 使分子获得较高的 $\mathrm{S}_{1}$ 态 能级. 而通过控制分子内共轭长度, 可以有效调控发光 波长. 一般而言, $\pi$ 共轭长度越长, 分子越倾向于长波 


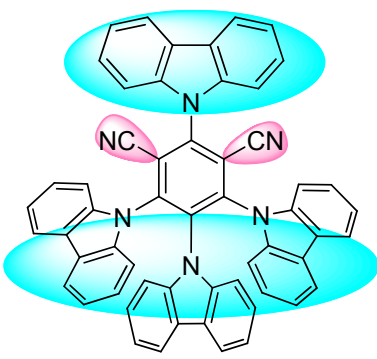

(a)

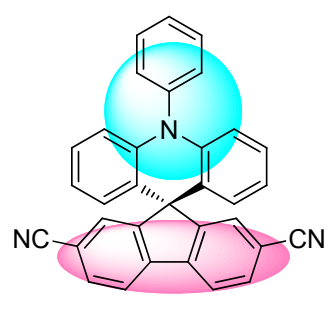

(b)

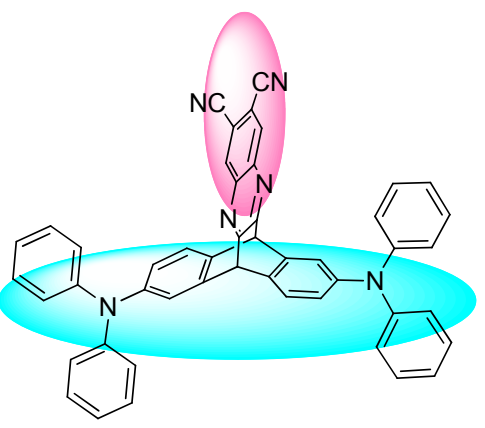

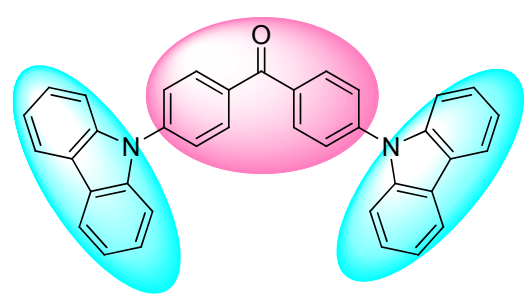

(c)

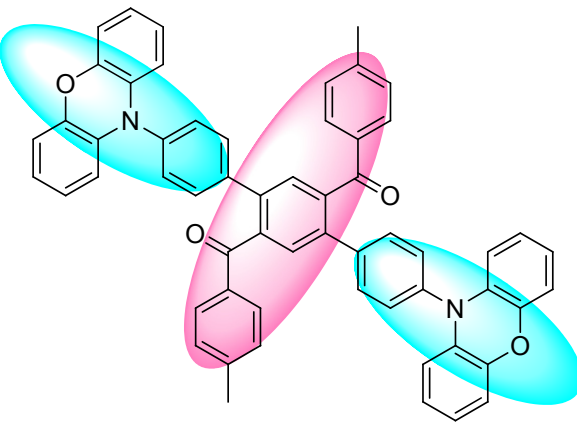

图 3 获得小 $\Delta E_{\mathrm{ST}}$ 的分子设计策略

Figure 3 Design strategies for obtaining a small $\Delta E_{\mathrm{ST}}$<smiles>c1ccc(-c2cccc(-n3c4ccccc4n(-c4ccccc4)c4ccc(N(c5ccccc5)c5ccccc5)cc4p3-c3cccc(-c4ccccc4)c3)c2)cc1</smiles>

(d) 素原子, 如 Eq. 1 所示.

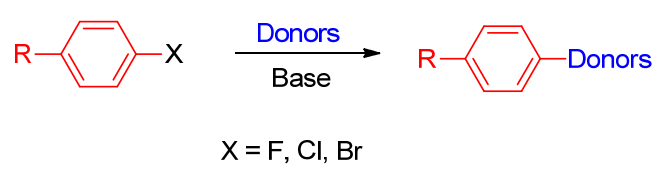

\section{D-A 型热活化延迟苂光蓝光分子及其 OLED}

为了获得足够小的 $\Delta E_{\mathrm{ST}}$, D-A 型 TADF 蓝光材料可 以通过引入适当的电子给体和电子受体以及巧妙利用 分子的几何构型、键接方式以产生空间阻碍作用, 使电 子给受体呈现较大的二面角, 实现 HOMO 和 LUMO 能 级的空间分离. 另一方面, 分子 $\mathrm{S}_{1}$ 态能级需要 $>2.9 \mathrm{eV}$ 以获得较纯蓝色光. 所以在选择电子给体和受体方面需 要巧妙合理设计. 下文将详细介绍常见的 D-A 型 TADF 蓝光材料及其在 OLED 器件的应用, 主要包括以 1,3,5三嗪类、1,3,4-惡二唑及 $1,2,4$-三唑类、嘧啶类、氮杂环 并菲类等含氮杂环化合物以及二苯甲酮类、氰基类、芳 基硼类和砜类及其衍生物作为电子受体的 D-A 型 TADF 蓝光材料及 OLED 器件. 所述 TADF 蓝光材料及其 OLED 器件光电性质数据列于表 1 . 
表 1 分子在溶液中或分散在主体薄膜或非掺杂成膜中光致发光波长 $\left(\lambda_{\mathrm{PL}}\right)$ 、氮气环境下荧光量子产率(PLQY)、室温环境下苂光寿 命 $\left(\tau_{\mathrm{PF}}, \tau_{\mathrm{DF}}\right)$ 、单重态-三重态能级差 $\left(\Delta E_{\mathrm{ST}}\right)$ 、电致发光波长 $\left(\lambda_{\mathrm{EL}}\right)$ 、最大外量子效率 $(\mathrm{EQE})$ 以及 $\mathrm{CIE}$ 色坐标

Table 1 PL peak $\left(\lambda_{\mathrm{PL}}\right)$ in solution or dispersed in a host film or in neat film, photoluminescence quantum yield (PLQY, under nitrogen), lifetime at room temperature $\left(\tau_{\mathrm{PF}}, \tau_{\mathrm{DF}}\right)$, singlet-triplet energy gap $\left(\Delta E_{\mathrm{ST}}\right)$, EL peak $\left(\lambda_{\mathrm{EL}}\right)$ and maximum EQE, CIE for TADF based blue emitters and OLEDs

\begin{tabular}{|c|c|c|c|c|c|c|c|c|c|}
\hline Compound & $\lambda_{\mathrm{PL}} / \mathrm{nm}$ & PLQY/\% & $\tau_{\mathrm{PF}} / \mathrm{ns}$ & $\tau_{\mathrm{DF}} / \mu \mathrm{s}$ & $\Delta E_{\mathrm{ST}} / \mathrm{eV}$ & $\lambda_{\mathrm{EL}} / \mathrm{nm}$ & EQE/\% & CIE & Ref. \\
\hline 1 & $466^{b}, 492^{a}$ & $35,39^{a}$ & $12,10^{a}$ & $120,230^{a}$ & 0.080 & 506 & 5.3 & - & [26] \\
\hline 2 & $457,480^{a}$ & $74^{d}$ & 6.3 & - & $0.09,0.11^{a}$ & $487^{a}$ & $20.6^{g}$ & $0.19,0.35$ & [27] \\
\hline 3 & $458,475^{a}$ & $57^{d}$ & 6.0 & - & $0.28,0.19^{a}$ & $478^{a}$ & $16.8^{g}$ & $0.17,0.27$ & [27] \\
\hline 4 & $458,475^{a}$ & $72^{d}$ & 6.5 & - & $0.032,0.29^{a}$ & $477^{a}$ & $14.6^{g}$ & $0.18,0.28$ & [27] \\
\hline 5 & 435 & 62 & 27 & 22 & 0.06 & 485 & 11 & - & [28] \\
\hline 6 & - & $16.7^{c}$ & - & 3.9 & 0.1 & 470 & $9.3^{f}$ & $0.15,0.22$ & [29] \\
\hline 7 & - & $50.5^{c}$ & - & - & 0.03 & 484 & $14.7^{f}$ & $0.17,0.34$ & [29] \\
\hline 8 & - & $43.0^{c}$ & - & - & 0.01 & 480 & $12.3^{f}$ & $0.17,0.31$ & [29] \\
\hline 9 & - & $40^{e}$ & - & 13.4 & 0.17 & 486 & $23.6^{f}$ & $0.21,0.36$ & [30] \\
\hline 10 & - & $97.9^{c}$ & - & 5.4 & 0.002 & 477 & $20.4^{f}$ & $0.18,0.31$ & [31] \\
\hline 11 & - & $31.1^{c}$ & - & 29.6 & 0.191 & 473 & $13.2^{f}$ & $0.17,0.25$ & [31] \\
\hline 12 & - & $85.3^{c}$ & - & 31.2 & 0.302 & 465 & $16.7^{f}$ & $0.15,0.18$ & [31] \\
\hline 13 & 495 & $29.8^{d}$ & 11.0 & 4.73 & - & - & - & - & [35] \\
\hline 14 & $502,510^{a}$ & $43.1^{d}, 87^{a, d}$ & $21.1,11.2^{a}$ & $13.3,520^{a}$ & 0.15 & 508 & $14.9^{g}$ & - & [35] \\
\hline 15 & $577,550^{a}$ & $12^{d}, 45^{a, d}$ & $9.0,7.0^{a}$ & $0.52,5.4^{a}$ & 0.08 & 580 & $9.5^{g}$ & - & [36] \\
\hline 16 & 528 & $7^{d}, 44^{a, d}$ & 3.9 & 33 & 0.02 & - & $9.2^{g}$ & - & [36] \\
\hline 17 & 495 & $4,12^{a, d}$ & 3.6 & - & 0.08 & - & $4.3^{g}$ & - & {$[36]$} \\
\hline 18 & $428^{b}$ & $75 \pm 2^{b, e}$ & - & - & 0.5 & - & $6.8^{h}$ & $0.158,0.043$ & [37] \\
\hline 19 & $458,464^{a}$ & $87^{a, e}$ & $12^{a}$ & $38^{a}$ & 0.25 & 470 & $20.4^{g}$ & $0.15,0.15$ & [40] \\
\hline 20 & $451,452^{a}$ & $69^{a, e}$ & $11^{a}$ & $40^{a}$ & 0.25 & 462 & $12.2^{g}$ & $0.15,0.12$ & [40] \\
\hline 21 & $461,466^{a}$ & $91^{a, e}$ & $13^{a}$ & $45^{a}$ & 0.26 & 469 & $17.1^{g}$ & $0.15,0.18$ & {$[40]$} \\
\hline 22 & $454,458^{a}$ & $90^{a, e}$ & $11^{a}$ & $70^{a}$ & 0.29 & 460 & $14.3^{g}$ & $0.15,0.13$ & [40] \\
\hline 23 & $448,457^{a}$ & $83^{a, e}$ & $11^{a}$ & $78^{a}$ & 0.30 & 458 & $11.4^{g}$ & $0.15,0.13$ & {$[40]$} \\
\hline 24 & $453,458^{a}$ & $54^{e}, 92^{a, e}$ & $11^{a}$ & $330^{a}$ & $0.26^{a}$ & 468 & $19.0^{h}$ & $0.16,0.21$ & [41] \\
\hline 25 & $456,462^{a}$ & $50^{e}, 94^{a, e}$ & $11^{a}$ & $210^{a}$ & $0.24^{a}$ & 472 & $20.8^{h}$ & $0.16,0.24$ & [41] \\
\hline 26 & 498 & $77^{a, e}$ & - & $21.4^{a}$ & $0.18^{a}$ & 499 & 20.9 & $0.21,0.44$ & [42] \\
\hline 27 & 498 & $79^{a, e}$ & - & $20.7^{a}$ & $0.19^{a}$ & 498 & 19.0 & $0.21,0.44$ & [42] \\
\hline 28 & 489 & $80^{a, e}$ & - & $26.2^{a}$ & $0.19^{a}$ & 489 & 24.5 & $0.19,0.37$ & [42] \\
\hline 29 & $503,492^{a}$ & $26^{e}, 49^{a, e}$ & - & - & 0.16 & 496 & $7.5^{h}$ & - & [47] \\
\hline 30 & $490,483^{a}$ & $36^{e}, 52^{a, e}$ & - & - & 0.13 & 486 & $8.7^{h}$ & - & [47] \\
\hline 31 & $532,499^{a}$ & $77^{e}, 77^{a, e}$ & 50 & 18.1 & 0.26 & 499 & $7.5^{h}$ & - & [47] \\
\hline 32 & $428^{b}$ & $75 \pm 2^{b, e}$ & - & - & 0.5 & - & $6.8^{h}$ & $0.158,0.043$ & [37] \\
\hline 33 & $420^{b}$ & $43^{e}$ & - & - & - & - & $3.5^{h}$ & $0.156,0.058$ & [37] \\
\hline 34 & 485 & $45^{b, d}, 81^{a, d}$ & 175 & 5.3 & 0.04 & 490 & $16.5^{g}$ & $0.17,0.30$ & {$[50]$} \\
\hline 35 & $438,444^{a}$ & $21^{e}, 55^{a, e}$ & - & 7.1 & 0.21 & 446 & $8.1^{h}$ & $0.16,0.14$ & [18] \\
\hline 36 & $462,475^{a}$ & $38^{e}, 73^{a, e}$ & - & 4.6 & 0.14 & 484 & $14.3^{h}$ & $0.17,0.27$ & [18] \\
\hline 37 & $509,538^{a}$ & $44^{e}, 70^{a, e}$ & - & 0.12 & 0.03 & 539 & $10.7^{h}$ & $0.37,0.58$ & {$[18]$} \\
\hline 38 & $566,541^{a}$ & $36^{e}, 71^{a, e}$ & - & 0.13 & 0.10 & 586 & $4.2^{h}$ & $0.58,0.36$ & [18] \\
\hline 39 & $600,555^{a}$ & $10^{e}, 36^{a, e}$ & - & 0.03 & 0.06 & 548 & $6.9^{h}$ & $0.49,0.51$ & {$[18]$} \\
\hline 40 & 496 & $46^{a, d}$ & - & 925 & 0.05 & 504 & $10^{g}$ & - & [19] \\
\hline 41 & - & $37^{e}, 63^{a, e}$ & - & 3.1 & 0.16 & 481 & $23.3^{f}$ & $0.21,0.34$ & {$[30]$} \\
\hline 42 & $468,469^{a}$ & $70^{a, e}$ & $134^{a}$ & $48.16^{a}$ & 0.06 & 484 & $11.4^{h}$ & $0.174,0.310$ & {$[51]$} \\
\hline 43 & $490,514^{a}$ & $88.0^{c}$ & 15 & 0.6 & 0.03 & 488 & $24.0^{f}$ & $0.17,0.36$ & {$[52]$} \\
\hline 44 & $508,518^{a}$ & $91.4^{c}$ & 18 & 1.0 & 0.04 & 514 & $27.2^{f}$ & $0.30,0.64$ & {$[52]$} \\
\hline 45 & $467,467^{a}$ & $90^{a, e}$ & 6.2 & 0.2 & 0.06 & 474 & $18.4^{f}$ & $0.16,0.25$ & [53] \\
\hline 46 & 473 & $46.5^{c}, 89^{b, c}$ & 28.5 & $166,273^{b}$ & 0.34 & 470 & $8.0^{f}$ & - & {$[15,54,55]$} \\
\hline 47 & 447 & $35^{e}$ & - & $1.2^{b}$ & 0.05 & 462 & $16.4^{f}$ & $0.17,0.30$ & {$[56]$} \\
\hline 48 & $473^{a}$ & $94.6^{e}, 85^{a, e}$ & - & 2.60 & 0.13 & 486 & $12.1^{g}$ & - & [57] \\
\hline 49 & $475^{a}$ & $94.0^{e}, 85^{a, e}$ & - & 1.98 & 0.17 & 486 & $11.8^{g}$ & - & [57] \\
\hline 50 & 470 & $87^{e}$ & - & 2.35 & 0.11 & 510 & $17.9^{h}$ & $0.29,0.52$ & {$[58]$} \\
\hline
\end{tabular}




\begin{tabular}{|c|c|c|c|c|c|c|c|c|c|}
\hline Compound & $\lambda_{\mathrm{PL}} / \mathrm{nm}$ & PLQY/\% & $\tau_{\mathrm{PF}} / \mathrm{ns}$ & $\tau_{\mathrm{DF}} / \mu \mathrm{s}$ & $\Delta E_{\mathrm{ST}} / \mathrm{eV}$ & $\lambda_{\mathrm{EL}} / \mathrm{nm}$ & EQE/\% & CIE & Ref. \\
\hline 51 & 448 & $66^{e}$ & - & 2.96 & 0.16 & 475 & $21.8^{h}$ & $0.17,0.29$ & {$[58]$} \\
\hline 52 & 444 & $61^{e}$ & - & 4.21 & 0.21 & 473 & $19.5^{h}$ & $0.16,0.23$ & [58] \\
\hline 53 & 443 & $76^{e}, 74^{b, e}$ & - & 28 & 0.06 & 463 & $17.8^{h}$ & $0.16,0.19$ & [59] \\
\hline 54 & 453 & $81^{e}, 100^{b, e}$ & - & 17 & 0.06 & 471 & $20.0^{h}$ & $0.16,0.25$ & [59] \\
\hline 55 & 458 & $46^{e}$ & - & $24.34^{a}$ & 0.27 & 456 & $14^{g}$ & $0.14,0.12$ & [60] \\
\hline 56 & 453 & $76^{e}$ & - & $24.34^{a}$ & 0.27 & 460 & $4.8^{g}$ & - & [60] \\
\hline 57 & 450 & $63^{e}$ & 41 & 173 & 0.36 & 465 & $8.7^{f}$ & $0.15,0.18$ & [61] \\
\hline 58 & 499 & $86^{e}$ & 35 & 5.1 & 0.20 & 504 & $18.9^{f}$ & $0.23,0.50$ & [61] \\
\hline 59 & 455 & $46.6^{a, e}$ & 14.2 & 57.9 & 0.02 & 500 & $19.9^{f}$ & $0.22,0.40$ & [62] \\
\hline 60 & 455 & $54.9^{a, e}$ & 10.5 & 12.9 & 0.01 & 484 & $17.4^{f}$ & $0.18,0.32$ & [62] \\
\hline 61 & 448 & $49.7^{e}$ & - & 46.6 & 0.04 & 475 & $21.2^{f}$ & $0.20,0.35$ & [63] \\
\hline 62 & $488,490^{a}$ & $34.5^{e}, 91.6^{a, e}$ & $10.4^{a}$ & 19.3 & 0.19 & - & $23.9^{h}$ & $0.24,0.49$ & [64] \\
\hline 63 & $504,495^{a}$ & $30.6^{e}, 89.3^{a, e}$ & $10.7^{a}$ & 14.5 & 0.18 & - & $23.1^{h}$ & $0.28,0.54$ & [64] \\
\hline 64 & $562,550^{a}$ & $48.9^{e}, 90.4^{a, e}$ & $26.7^{a}$ & 1.9 & 0.032 & - & $29.2^{h}$ & $0.43,0.55$ & [64] \\
\hline 65 & $524,526^{a}$ & $31.1^{e}, 100^{a, e}$ & $15.7^{a}$ & 11.6 & 0.09 & - & $31.3^{h}$ & $0.32,0.59$ & [64] \\
\hline 66 & $543,541^{a}$ & $54.5^{e}, 95^{a, e}$ & $23.7^{a}$ & 5.2 & 0.04 & - & $30.6^{h}$ & $0.34,0.57$ & [64] \\
\hline 67 & $462,470^{a}$ & $17.8^{e}, 36^{a, e}$ & $6.99^{a}$ & 0.03 & 0.439 & - & $5.7^{h}$ & $0.17,0.18$ & [64] \\
\hline 68 & $431,436^{a}$ & $11.2^{e}, 15^{a, e}$ & $6.53^{a}$ & 0.01 & 0.403 & - & $1.6^{h}$ & $0.16,0.06$ & [64] \\
\hline 69 & 519 & $31.34^{e}$ & 5.09 & 8.01 & 0.03 & - & $1.50^{f}$ & $0.16,0.28$ & [65] \\
\hline 70 & 450 & $31.12^{e}$ & 3.86 & 7.47 & 0.02 & - & $4.01^{f}$ & $0.15,0.14$ & [65] \\
\hline 71 & $509,504^{a}$ & $44^{d}, 92^{a, d}$ & - & - & 0.071 & 502 & $22.8^{g}$ & $0.22,0.55$ & {$[66]$} \\
\hline 72 & $495,487^{a}$ & $84^{d}, 100^{a, d}$ & - & - & 0.058 & 492 & $21.6^{g}$ & $0.18,0.43$ & [66] \\
\hline 73 & $477,477^{a}$ & $91^{d}, 87^{a, d}$ & - & - & 0.062 & 488 & $14.0^{g}$ & $0.22,0.55$ & [66] \\
\hline 74 & 475 & $100^{d}$ & 33 & 1.60 & 0.10 & 480 & $21.7^{g}$ & $0.14,0.23$ & [67] \\
\hline 75 & 456 & $76^{d}$ & 28 & 4.02 & 0.12 & 475 & $19.0^{g}$ & $0.14,0.12$ & [67] \\
\hline 76 & 451 & $56^{d}$ & 26 & 2.06 & 0.06 & 465 & $20.1^{g}$ & $0.15,0.09$ & [67] \\
\hline 77 & 443 & $86^{d}$ & 21 & 3.49 & 0.12 & 465 & $13.3^{g}$ & $0.15,0.08$ & [67] \\
\hline 78 & 467 & $99^{e}$ & 19 & 91 & 0.24 & 473 & $18.2^{f}$ & $0.15,0.23$ & [68] \\
\hline 79 & - & - & - & - & - & - & - & - & [69] \\
\hline 80 & $440^{a}$ & $98^{a, d}$ & - & 2.36 & 0.013 & 466 & $15.1^{f}$ & - & [69] \\
\hline 81 & $482^{a}$ & $99^{a, d}$ & - & 1.87 & 0.028 & 503 & $22.1^{f}$ & - & [69] \\
\hline 82 & - & - & - & - & 0.456 & - & - & - & [70] \\
\hline 83 & 484 & $89.0^{d}$ & 41.4 & 6.71 & 0.041 & 479 & $16.0^{f}$ & $0.14,0.24$ & [70] \\
\hline 84 & 540 & $87.0^{d}$ & 42.8 & 1.98 & 0.033 & 525 & $17.3^{f}$ & $0.28,0.58$ & [70] \\
\hline 85 & 446 & $81^{a, d}$ & 47.8 & 4.15 & 0.040 & - & - & $0.14,0.09$ & [71] \\
\hline 86 & 462 & $81^{a, d}$ & 25.0 & 3.70 & 0.057 & - & - & $0.14,0.15$ & [71] \\
\hline 87 & $402,421^{a}$ & $57^{e}, 60^{a, e}$ & $2.2,3.5^{a}$ & $90,850^{a}$ & 0.54 & 420 & $2.9^{f}$ & - & [72] \\
\hline 88 & $419,430^{a}$ & $65^{e}, 66^{a, e}$ & $3.1,3.2^{a}$ & $140,840^{a}$ & 0.45 & 425 & $5.6^{f}$ & - & [72] \\
\hline 89 & $404,423^{a}$ & $69^{e}, 80^{a, e}$ & $5.3,7.6^{a}$ & $270,2600^{a}$ & 0.32 & 400 & $9.9^{f}$ & $0.15,0.07$ & [72] \\
\hline 90 & 445 & $56^{d}$ & - & 127 & 0.21 & 460 & $14.5^{f}$ & $0.16,0.16$ & [73] \\
\hline 91 & 426 & $64^{d}$ & 6.5 & 347,2530 & 0.25 & 428 & - & $0.15,0.12$ & [74] \\
\hline 92 & 439 & $52^{d}$ & 8.7 & 378,2860 & 0.17 & 440 & - & $0.19,0.15$ & [74] \\
\hline 93 & 461 & $56.3^{e}$ & - & 1.23 & 0.19 & 460 & 11.7 & $0.18,0.19$ & [75] \\
\hline 94 & 434 & $69.3^{e}$ & - & 1.16 & 0.26 & 435 & 5.5 & $0.15,0.08$ & [75] \\
\hline 95 & $451,458^{a}$ & $48^{e}, 98^{a, e}$ & 29 & 2.7 & 0.06 & 486 & $20.5^{f}$ & $0.16,0.26$ & [76] \\
\hline
\end{tabular}

${ }^{a}$ Dispersed in a host film. ${ }^{b}$ Neat film. ${ }^{c}$ Calculated from the PL measurement. ${ }^{d}$ Absolute PLQY from spectrometer measurement. ${ }^{e}$ Absolute PLQY from integrating sphere measurement. ${ }^{f}$ Calculated from the current density, luminance and EL measurement. ${ }^{g}$ Absolute Maxmuim EQE from spectrometer measurement. ${ }^{h}$ Absolute Maxmuim EQE from integrating sphere measurement.

\section{1 氮杂环类 D-A 型 TADF 蓝光材料}

\subsubsection{1,3,5-三嗪类 D-A 型 TADF 蓝光材料}

$1,3,5-$ 三嗪由于含有三个亚胺氮 $(\mathrm{C}=\mathrm{N})$, 呈现出高 度缺电子的性质, 而三嗪环上三个与氮原子相邻的活性 位点为对其做进一步修饰提供了多样性和便捷性, 所以
1,3,5-三嗪衍生物被广泛用作电子受体构建 D-A 型 TADF 蓝光材料. 2011 年, Adachi 等 ${ }^{[26]}$ 首次利用大体积的 苯基吲哚并咔唑作为给体, 合成了 $1,3,5$-三嗪基蓝光 TADF 材料 1. 利用给体与受体之间的空间位阻, 使分子 的 HOMO 和 LUMO 能级分别分散在吲哚并咔唑和三嗪 
基团上. 能级的有效分离使 $\mathbf{1}$ 获得较小的 $\Delta E_{\mathrm{ST}}(0.11 \mathrm{eV})$ 的同时得到了较高的 $k_{\mathrm{r}}\left(\approx 10^{7}\right)$. 以质量分数为 $6 \%(6$ $\mathrm{wt} \%)$ 的 $\mathbf{1}$ 掺杂在 $\mathrm{mCP}$ 薄膜上显示的光致发光光谱中, $\mathrm{PF}$ 寿命和 $\mathrm{DF}$ 寿命分别为 $10 \mathrm{~ns}$ 和 $230 \mu \mathrm{s}$. 器件结构为 $\mathrm{ITO} / \alpha-\mathrm{NPD} / \mathrm{mCP} / \mathrm{mCP}: 1 \quad(6 \mathrm{wt} \%) / \mathrm{BP} 4 \mathrm{mPy} / \mathrm{LiF} / \mathrm{Al}(\mathrm{mCP}$ 为主体材料), 最大器件 $\mathrm{EQE}$ (下文所述 $\mathrm{EQE}$ 均为器件最 大值)为 $5.3 \%$. 为了进一步探究不同电子给体对分子 HOMO 的分散程度以及对 TADF 蓝光分子光电性能的 影响, 该团队 ${ }^{[27]}$ 设计了三种均以 2,4,6-三苯基-1,3,5-三 嗪作为电子受体不同的咔唑衍生物作为电子给体的 $\mathrm{TADF}$ 蓝光分子 $2 \sim \mathbf{4}$. 测量三种分子的振子强度 $F$ 、跃 迁偶极矩 $Q$ 、荧光辐射衰减率 $k_{\mathrm{r}} \mathrm{PLQY}$ 以及 $\Delta E_{\mathrm{ST}}$ 值, 发 现由于电子给体体积最大的 2 分子中, 电子给体与受体 之间的空间位阻导致 HOMO 和 LUMO 能级分离程度更 大, 获得最小的 $\Delta E_{\mathrm{ST}}(0.09 \mathrm{eV})$ 值和最大的 $F$ 值, $k_{\mathrm{r}}$ 值以 及 PLQY (74\%). 基于上述三种蓝光 TADF 分子设计的 器件结构为 ITO $(120 \mathrm{~nm}) / m$-CBP $(10 \mathrm{~nm}) / \mathrm{DPEPO}: \mathbf{2} \sim \mathbf{4}$ $(6 \mathrm{wt} \%, 15 \mathrm{~nm}) / \mathrm{DPEPO}(10 \mathrm{~nm}) / \mathrm{TPBi}(30 \mathrm{~nm}) / \mathrm{LiF}(0.8$ $\mathrm{nm}) / \mathrm{Al}$, 以 DPEPO 为主体材料, $m$-CBP 为空穴传输材 料, 其中 2 也获得最高的 $\mathrm{EQE}(20.6 \%), 3,4$ 依次为
$16.8 \%$ 和 $14.6 \%$.

次年, 该团队 ${ }^{[28]}$ 以 2-苯基-1,3,5-三嗪基团作为电子 受体, 3,3'-联咔坐作为电子给体, 合成分子 5. 同样通过 两者的空间位阻作用使分子获得更小的 $\Delta E_{\mathrm{ST}}$ 值 $(0.06$ $\mathrm{eV})$, 并表明二咔唑比单咔唑具有更好的降低分子 HOMO, LUMO 能级重叠作用. 通过测试分子在非极性 溶剂环已烷和极性溶剂四氢呋喃中的荧光光谱, 发现明 显的红移及吸收强度下降现象, 表明分子在激发态时偶 极矩发生变化, 证实从二咔唑转移到三嗪中心的分子内 电子转移现象. 器件结构为 ITO $/ \alpha-\mathrm{NPD}(40 \mathrm{~nm}) / \mathbf{5}: \mathrm{mCP}$ $(6 \mathrm{wt} \%, 10 \mathrm{~nm}) / \mathbf{5}:$ DPEPO $(6 \mathrm{wt} \%, 20 \mathrm{~nm}) / \mathrm{DPEPO}(10$ $\mathrm{nm}) / \mathrm{TPBi}(30 \mathrm{~nm}) / \mathrm{LiF}(0.8 \mathrm{~nm}) / \mathrm{Al}(80 \mathrm{~nm}), \mathbf{5}$ 分别分散在 空穴传输型主体 $\mathrm{mCP}$ 和电子传输型主体 DPEPO 中, 以 达到扩大载流子复合区的效果，获得了更高的最大 EQE $(11 \% \pm 1 \%)$.

2016 年, Gong 等 ${ }^{[29]}$ 将咔唑衍生物与 2,4,6-三苯基1,3,5-三嗪组合, 制备了 $\mathbf{6} \sim \mathbf{8}$ 三种蓝光 TADF 分子, 并 得到更小的 $\Delta E_{\mathrm{ST}}$ 值 $(0.1,0.03$ 和 $0.01 \mathrm{eV})$. 通过测量三种 化合物的单晶结构, 发现咔唑单元与电子受体苯基平面 之间的扭转角均约为 $87^{\circ}$, 而三嗪单元与苯环平面的扭

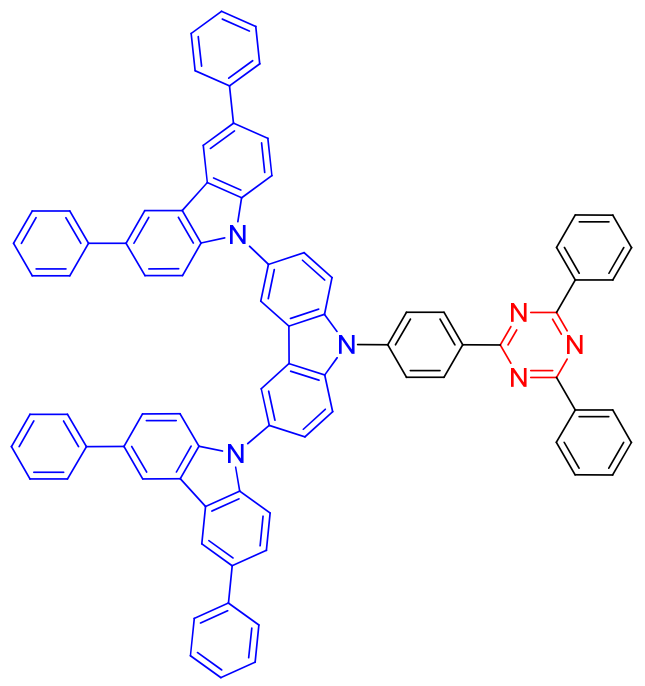

2

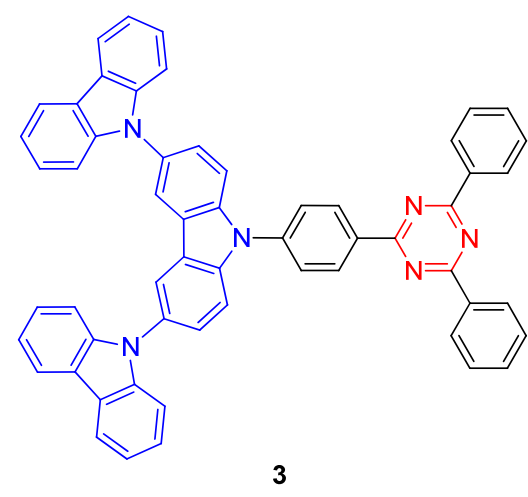

3

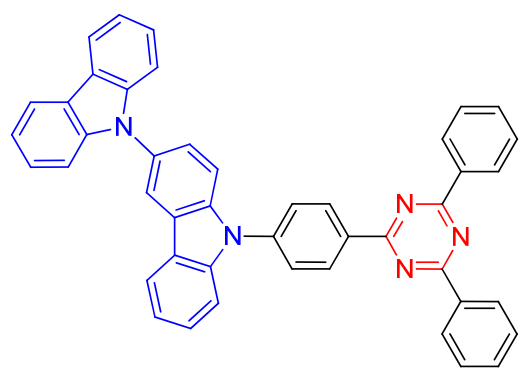

4

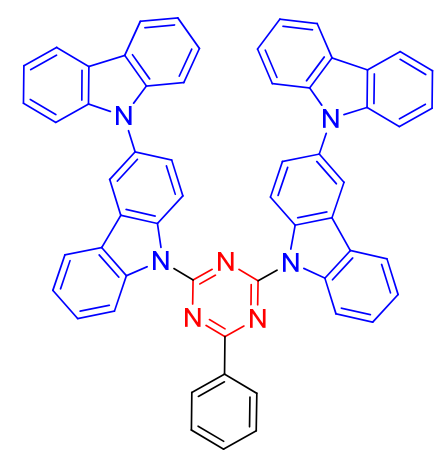

5 

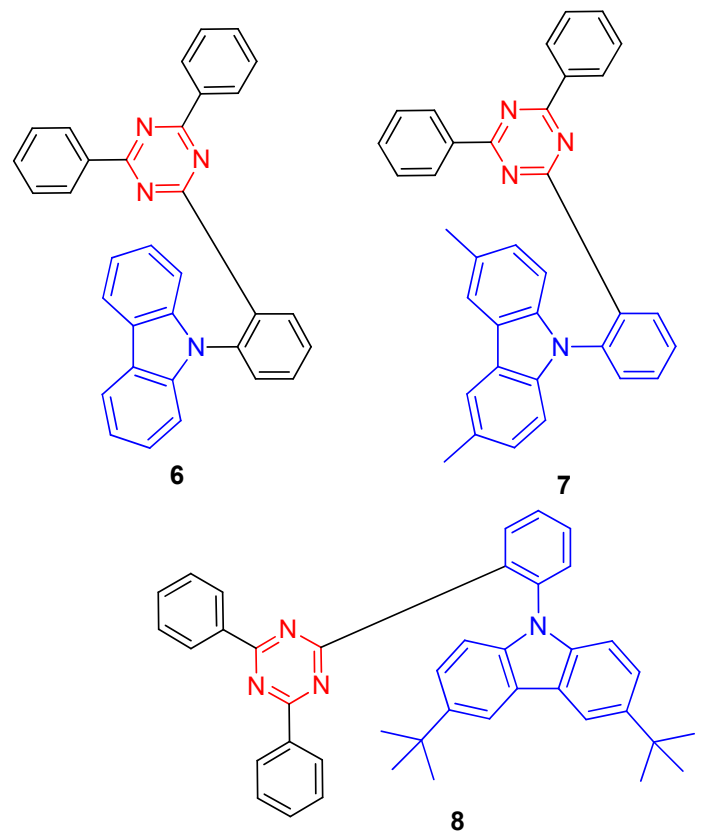

转角均约为 $34^{\circ}$, 由于在咔唑单元上修饰不同的具有给电 子作用的烷基取代基, 导致咔唑的给电子作用强度不一 致, 用叔丁基修饰咔唑单元所得的 8 表现出最小的 $\Delta E_{\mathrm{ST}}$ 值, 并且发光波长发生相应的红移. 表明通过在电子给 体上引入具有一定空间阻碍作用的取代基团, 如甲基、叔 丁基等, 可以在一定程度上降低分子的 $\Delta E_{\mathrm{ST}}$ 值, 有利于 获得高效的 RISC 过程, 但由于分子间具有更强电子推拉 作用，使分子更容易出现红移，不利于深蓝光材料的合 成. 基于 3 种化合物的 OLED 器件结构为 ITO $(50 \mathrm{~nm}) /$ PEDOT:PSS $(60 \mathrm{~nm}) / \mathrm{TAPC}(20 \mathrm{~nm}) / \mathrm{mCP}(10 \mathrm{~nm}) / \mathrm{mCP}$ : 6 $\sim 8(5 \%, 25 \mathrm{~nm}) / \mathrm{TSPO} 1(35 \mathrm{~nm}) / \mathrm{TPBi} / \mathrm{LiF}(1 \mathrm{~nm}) / \mathrm{Al}$ $(200 \mathrm{~nm})$, 最大 $\mathrm{EQE}$ 分别为 $9.3 \%, 14.7 \%$ 和 $12.3 \%$.

2016 年, Lee 等 ${ }^{[30]}$ 将 9-苯基-3,3'-联咔唑作为给体连 接到 2,4,6-三苯基-1,3,5-三嗪受体中心制备了 $\Delta E_{\mathrm{ST}}$ 仅为 $0.17 \mathrm{eV}$ 的分子 9. 利用该分子制作的蓝光器件结构为

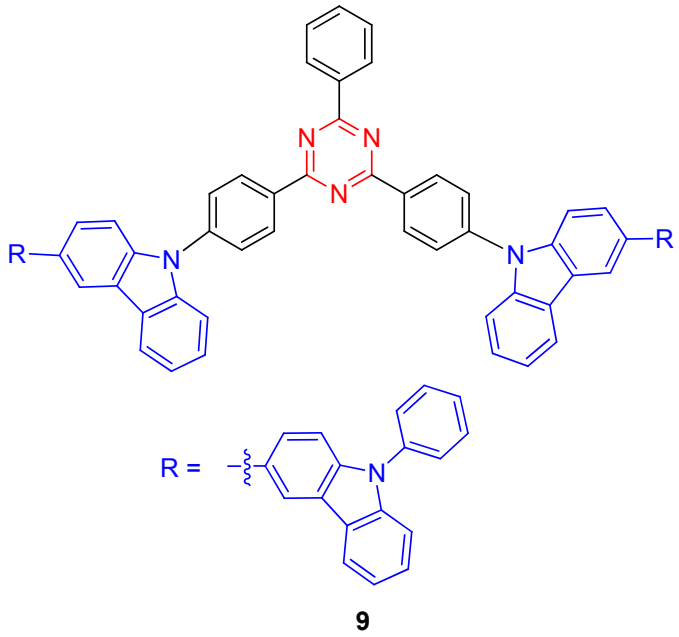

ITO $(120 \mathrm{~nm}) /$ PEDOT:PSS $(60 \mathrm{~nm}) /$ TAPC $(20 \mathrm{~nm}) / \mathbf{9}$ : DPEPO $(25 \mathrm{~nm}) / \mathrm{TSPO} 1(5 \mathrm{~nm}) / \mathrm{TPBi}(30 \mathrm{~nm}) / \mathrm{LiF}(1.5$ $\mathrm{nm}) / \mathrm{Al}(200 \mathrm{~nm})$, 器件最大 EQE 高达 23.6\%.

同年，该团队 ${ }^{[31]}$ 以 2,4,6-三苯基-1,3,5-三嗪为电子 受体, 分别以邻位、间位以及对位三种方式键接苯并呋 喃咔唑电子给体合成了三种空间阻碍作用依次递减的 蓝光 TADF 分子 $10 \sim 12$, 均获得很小的 $\Delta E_{\mathrm{ST}}$. 其中邻位 取代的分子 10 获得最小值 $(0.002 \mathrm{eV})$ ，间位取代次之 $(0.191 \mathrm{eV})$, 而对位取代产物由于电子给受体之间空间 距离较远, 获得较大的 $\Delta E_{\mathrm{ST}}(0.302 \mathrm{eV})$. 三者在无氧甲 苯溶液下 PLQY 分别为 $97.9 \%, 31.1 \%$ 和 $85.3 \% .11$ 较大 的 $\Delta E_{\mathrm{ST}}$ 以及较小的振子强度导致其较小的荧光量子产 率. 三种分子以 ITO/PEDOT:PSS $(60.0 \mathrm{~nm}) / \mathrm{TAPC}(20.0$ $\mathrm{nm}) / \mathrm{mCP}(10.0 \mathrm{~nm}) / \mathbf{1 0} \sim \mathbf{1 2}$ :DPEPO $(25.0 \mathrm{~nm}) / \mathrm{TSPO} 1$ $(5.0 \mathrm{~nm}) / \mathrm{TPBi}(30.0 \mathrm{~nm}) / \mathrm{LiF}(1.5 \mathrm{~nm}) / \mathrm{Al}(200.0 \mathrm{~nm})$ 为结 构组成 OLED 器件测试其性能, 三种器件均发射较纯蓝 色光, CIE 色坐标分别为 $(0.18,0.31),(0.17,0.25)$ 和 $(0.15$, 0.18 ), 器件最大 $\mathrm{EQE}$ 分别为 $20.4 \%, 13.2 \%$ 和 $16.7 \%$. 其 中基于 $\mathbf{1 0}$ 的 OLED 器件荧光反应时间仅为 $5.4 \mu \mathrm{s}$, 在 $1000 \mathrm{~cd} / \mathrm{m}^{2}$ 电流密度下仅仅出现了 $2.7 \%$ 的效率滚降，成 为首例同时获得高外量子效率、低效率滚降以及长器件 寿命的 OLED 蓝光器件.

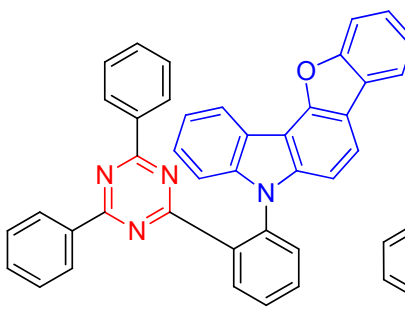

10<smiles></smiles>

11

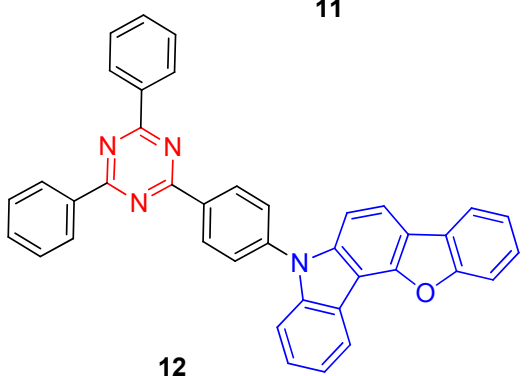

2.1.2 1,3,4-噁二唑及 1,2,4-三唑类 D-A 型 TADF 蓝 光材料

1,3,4-哑二唑衍生物及 $1,2,4$-三唑衍生物由于具有高 三重态能级，良好的吸电子性被广泛用作吸电子基团以 构建 D-A 型蓝光 TADF 分子, 并且由于其出众的电子注 入及传输能力, 十分适合用作构建 OLED 器件 ${ }^{[32 ~ 34]}$. 2013 年 Adachi 等 ${ }^{[35]}$ 报道了两种以吩噁嗪衍生物作为电 子给体 2,5-二苯基-1,2,4-硻二唑为电子受体的蓝光 
$\mathrm{TADF}$ 分子 $13 \sim 14$. 同样利用吩噁嗪的强给电子能力和 1,2,4-噁二唑的强电子接收能力, 使两者分子内发生良 好的电子转移, 以获得足够小的 $\Delta E_{\mathrm{ST}}$ 值 $(14$ 为 $0.15 \mathrm{eV})$. 两种分子的甲苯溶液在有氧和无氧(氮气鼓泡 $5 \mathrm{~min}$ )环 境下测试其荧光量子产率, 结果表明在无氧环境下 $\mathbf{1 3}$ 和 14 均表现出更高的荧光量子产率, 分别由 $18.1 \%$, $19.1 \%$ 提升到 $29.8 \%, 43.1 \%$. 两者的即时和延迟苂光寿 命, 均表现出类似升高. 苂光量子产率和荧光寿命在有 氧和无氧环境下的这种差异表明, 氧气可以淬灭三重态 激子从而降低 TADF 分子的苂光量子产率, 使延迟苂光 效果减弱. 并且由两者同样在无氧环境下的苂光量子产 率看出, 连接两个吩噁嗪给体的 14 比连接单个给体的 13 表现出更高的苂光强度, 表明双给体 D-A 分子比单 给体 D-A 分子具有更高的苂光量子产率. 基于分子 $\mathbf{1 4}$ 设计的 TADF 蓝光 OLED 结构为 ITO/ $\alpha$-NPD (30 $\mathrm{nm}) / \mathrm{mCP}(10 \mathrm{~nm}) / \mathbf{1 4}$ :DPEPO $(6 \mathrm{wt} \%, 15 \mathrm{~nm}) / \mathrm{DPEPO}(10$ $\mathrm{nm}) / \mathrm{TPBi}(40 \mathrm{~nm}) / \mathrm{LiF}(0.8 \mathrm{~nm}) / \mathrm{Al}(90 \mathrm{~nm})$ (DPEPO 为主 体材料), 其最大 $\mathrm{EQE}$ 为 $14.9 \%$.

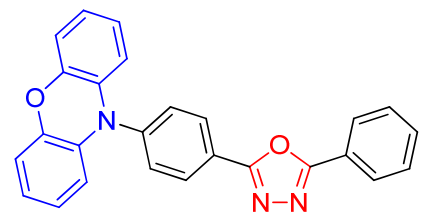

13

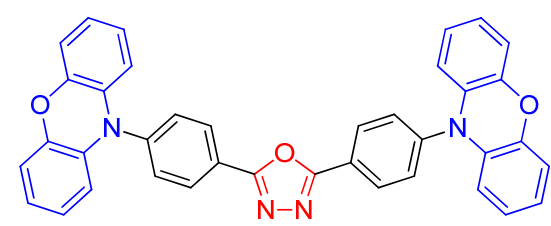

14

次年, 该团队 ${ }^{[36]}$ 以 1,3,4-悪二唑衍生物及 $1,2,4$ 三唑 衍生物作为电子受体设计 TADF 分子, 获得了性能更加 优异的蓝光 TADF 分子 $15 \sim 17$. 三个分子均以 5-苯基吩 嗪作为电子给体, 分别以 2,5-二苯基-1,3,4-惡二唑和 3,4,5-三苯基-1,2,4-三唑作为电子受体. 通过基于 B3LYP 函数方法的密度泛函理论模拟三种分子的基态 几何图形, 发现电子给体平面和电子受体的苯环平面之 间存在较大的二面角, 分子 HOMO 和 LUMO 能级之间 较低的重叠使三种分子获得较低的 $\Delta E_{\mathrm{ST}}$ 值 $(0.08,0.02$ 以 及 $0.08 \mathrm{eV})$. 以 $\mathrm{ITO} / \alpha-\mathrm{NPD}(40 \mathrm{~nm}) / \mathbf{1 5} \sim \mathbf{1 6}$ : CBP $(20$ $\mathrm{nm}) / \mathrm{TPBI}(60 \mathrm{~nm}) / \mathrm{LiF}(1 \mathrm{~nm}) / \mathrm{Al}$ 为结构的 OLED 的最大 $\mathrm{EQE}$ 分别为 $9.5 \%$ 和 $9.2 \%$; 另外, 蓝光分子 17 以 $\mathrm{ITO} /$ $\alpha$-NPD (30 nm)/TCTA (20 nm)/CzSi (10 nm)/17 (20 nm)/ DPEPO $(10 \mathrm{~nm}) / \mathrm{TPBI}(30 \mathrm{~nm}) / \mathrm{LiF}(1 \mathrm{~nm}) / \mathrm{Al}$ 为结构的 OLED 器件 最大 EQE 仅为 $4.3 \%$.

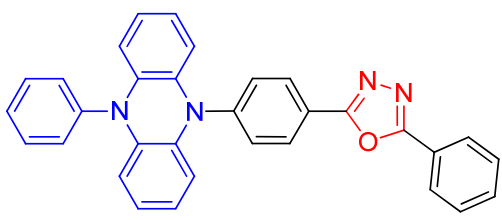

15

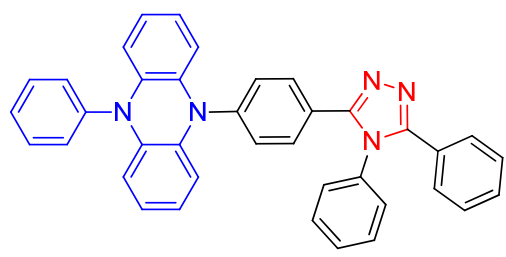

16

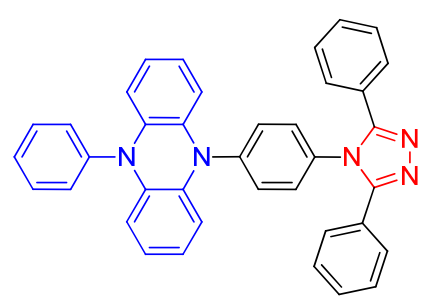

17

2016 年, $\mathrm{Li}$ 等 $^{[37]}$ 合成了一种以 1,2,4-三唑为电子给 体, 咔唑和三苯胺作为电子给体的蓝光分子 18. 该分子 表现出较大的 $\Delta E_{\mathrm{ST}}(0.5 \mathrm{eV})$, 但具有较高的 PLQY (75\%), 成膜状态下其发光波长为 $428 \mathrm{~nm}$, 且具有非常 窄的半峰宽 (55 nm), 意味着基于 18 组成的 OLED 器件 将发射十分纯的蓝色光. 结构为 $\mathrm{ITO} / \mathrm{MoO}_{3}(6 \mathrm{~nm}) / \mathrm{NPB}$ $(30 \mathrm{~nm}) / \mathbf{1 8}(20 \mathrm{~nm}) / \mathrm{TPBi}(50 \mathrm{~nm}) / \mathrm{LiF}(0.8 \mathrm{~nm}) / \mathrm{Al}(100$ $\mathrm{nm})$ 的 OLED 器件 CIE色坐标为 $(0.158,0.043)$, 且获得目 前为止 $\operatorname{CIE}(y)<0.06$ 的 OLED 器件中最高的 $\mathrm{EQE}$ (6.8\%). 值得一提的是, 器件在 $1000 \mathrm{~cd} \cdot \mathrm{m}^{-2}$ 电流密度下 仍然保持最大 $\mathrm{EQE}$ 的 $79 \%$, 即使在 $7323 \mathrm{~cd} \cdot \mathrm{m}^{-2}$ 下仍保 持 $66 \%$, 展示出非常优异的抗效率滚降的性质.

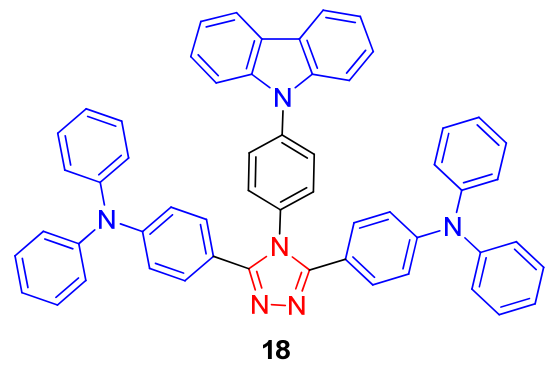

\subsection{3 嘧啶类 D-A 型 TADF 蓝光材料}

与 $1,3,5-$ 三嗪相似, 嘧啶环由于存在两个缺电子的 亚胺氮 $(\mathrm{C}=\mathrm{N})$, 展示出灵活的可修饰性及良好的电子亲 和力, 能与大多数具有较高三重态能级的电子给体单元 (如咔唑)之间产生良好的电子转移效应 ${ }^{[38]}$. 另一方面, 由于嘧啶环与咔唑, 噁二唑以及咪唑等单元相比, 具有 
更低的 LUMO 能级, 作为发光层在构建蓝光 OLED 器 件时能使电子注入过程更容易 ${ }^{[39]}$. 因此, 嘧啶衍生物被 广泛用于构建 D-A 型蓝光 TADF 分子及其 OLED 器件. 2017 年, Yasuda 等 ${ }^{[00]}$ 报道了一系列以嘧啶衍生物为电子 受体, 并以螺浐啶衍生物为电子给体的蓝光 TADF 分子 19 23. 螺呋啶单元上氢原子以及相邻苯环上的氢原子 之间存在较大的空间位阻作用使分子之间的电子给受 体表现出近乎正交的构型, 使 5 种分子均表现出较低的 $\Delta E_{\mathrm{ST}}$ 值 $(0.25 \sim 0.30 \mathrm{eV})$. 在氮气保护下, 5 种分子掺杂在 PPF 薄膜中获得了高达 $69 \% \sim 91 \%$ 的 PLQY, 并且在无 氧甲苯溶液中最大发光波长为 $448 \sim 461 \mathrm{~nm}$, 发射深蓝 色光. 基于上述良好的光学性能, Yasuda 等以 PPF 为主 体材料, 构建了结构为 ITO $(100 \mathrm{~nm}) /$ HAT-CN $(10$ $\mathrm{nm}) / \alpha$-NPD $(40 \mathrm{~nm}) / \mathrm{CCP}(5 \mathrm{~nm}) / \mathbf{1 9} \sim \mathbf{2 3}(20 \mathrm{~nm}) / \mathrm{PPF}(10$ $\mathrm{nm}) / \mathrm{TPBi}(30 \mathrm{~nm}) / \mathrm{Liq}(1 \mathrm{~nm}) / \mathrm{Al}(100 \mathrm{~nm})$ 的 OLED 器件, 以研究 5 种分子的光电性能. 结果显示, 5 种 OLED 器件 分别获得了 $20.4 \%, 12.2 \%, 17.1 \%, 14.3 \%$ 以及 $11.4 \%$ 的最 大 $\mathrm{EQE}$, 均发射出深蓝色光, CIE 色坐标分别为 $(0.16$, $0.23) ，(0.16,0.20) ，(0.16,0.21)$ 以及 $(0.16,0.19)$ 和 $(0.15$, $0.15)$. 此外, 5 种 OLED 器件的启动电压均较低, 为 3.5 $\mathrm{V}$ 左右.

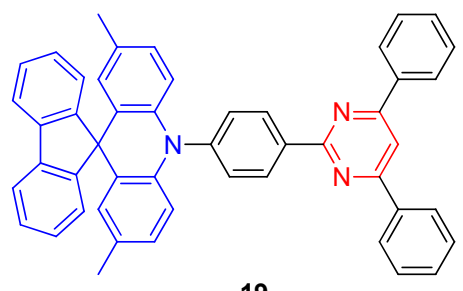

19

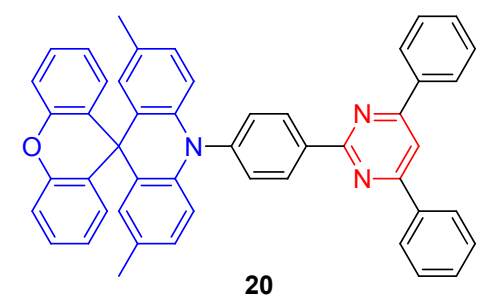

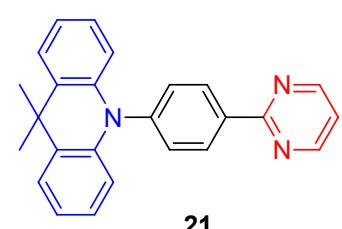

21
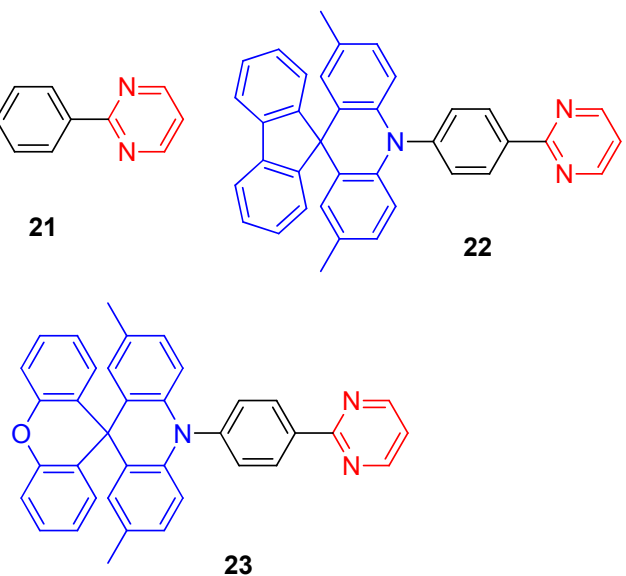

为了获得光电性能更加卓越的蓝光 TADF 分子及 OLED 器件, 该团队 ${ }^{[4]}$ 同样以嘧啶单元为电子受体, 二 苯基呋啶为电子给体, 通过在嘧啶中心连接两个电子给 体合成两种光电性能更优越的的蓝光 TADF 分子 $\mathbf{2 4}$ 和 25. 由于分子内空间阻碍作用十分显著, 听啶单元与相 连的苯环之间的扭转二面角达到 $82^{\circ} \sim 87^{\circ}$, 使 24 和 25 分别获得 0.16 和 $0.15 \mathrm{eV}$ 的 $\Delta E_{\mathrm{ST}}$ 值同时，获得了 $92 \%$ 和 $94 \%$ 的 PLQY (以质量分数 $18 \%$ 掺杂在 PPF 薄膜中). 此 外，两者的 PF 寿命均为 $11 \mathrm{ns,} \mathrm{DF}$ 寿命分别为 210 和 330 $\mathrm{ms}$. 基于 2 种高效蓝光延迟苂光分子组成的 OLED 器件 结构为 ITO $(100 \mathrm{~nm}) / \mathrm{HAT}-\mathrm{CN}(10 \mathrm{~nm}) / \alpha$-NPD $(40 \mathrm{~nm}) /$ CCP (5 nm)/24, 25 (18 wt $\%)$ :PPF (20 nm)/PPF (10 nm)/ TPBi $(30 \mathrm{~nm}) / \mathrm{Liq}(1 \mathrm{~nm}) / \mathrm{Al}(100 \mathrm{~nm})$, 两种器件在低电 流密度以及不提高光外耦合率的情况下分别获得 $19.0 \%$ 和 $20.8 \%$ 的最大 EQE, 且发射较纯的蓝色光, CIE 色坐标 分别为 $(0.16,0.21)$ 和 $(0.16,0.24)$. 此外, 两者表现出较 低的启动电压, 均为 $3.6 \mathrm{~V}$, 且分别获得 27.9 和 31.5 $\mathrm{lm} \cdot \mathrm{W}^{-1}$ 较高的发光效率.<smiles>Cc1nc(-c2ccc(N3c4ccccc4C(c4ccccc4)(c4ccccc4)c4ccccc43)cc2)cc(-c2ccc(N3c4ccccc4C(c4ccccc4)(c4ccccc4)c4ccccc43)cc2)n1</smiles><smiles></smiles>

同年, Kido 等 ${ }^{[42]}$ 同样以嘧啶衍生物为电子受体, 通 过中心嘧啶单元两侧连接 9,9-二甲基浐啶电子给体, 合 成了一系列新型的 TADF 分子 $\mathbf{2 6} \sim \mathbf{2 8}$, 三种分子具有较 小的 $\Delta E_{\mathrm{ST}}(0.18,0.19$ 和 $0.19 \mathrm{eV})$. 其中 28 在 DPEPO 薄 膜中展示出较高的发光强度(PLQY 为 $80 \%$ ) 以及毫秒级 的 DF 寿命 $(26 \mathrm{~ms})$. 以三种分子为发光层组成的 OLED 器件结构为 ITO/TAPC $(30 \mathrm{~nm}) / \mathbf{2 6} \sim \mathbf{2 8}(10 \mathrm{wt} \%)$ :DPEPO $(20 \mathrm{~nm}) / \mathrm{B} 3 \mathrm{PyPB}(50 \mathrm{~nm}) / \mathrm{LiF}(0.5 \mathrm{~nm}) / \mathrm{Al}(100 \mathrm{~nm}), \mathrm{CIE}$ 色坐标分别为 $(0.21,0.44),(0.21,0.44)$ 以及 $(0.19,0.37)$, 均发射较纯浅蓝色光. 三种器件最大 $\mathrm{EQE}$ 分别为 $20.9 \%, 19.0 \%$ 以及 $24.5 \%$. 值得一提的是，基于 28 的 
OLED 器件的启动电压仅为 $2.80 \mathrm{~V}$.<smiles>CC1(C)c2ccccc2N(c2ccc(-c3cc(-c4ccc(N5c6ccccc6C(C)(C)c6ccccc65)cc4)nnn3)cc2)c2ccccc21</smiles>

26<smiles>CC1(C)c2ccccc2N(c2ccc(-c3cc(-c4ccc(N5c6ccccc6C(C)(C)c6ccccc65)cc4)nc(-c4ccccc4)n3)cc2)c2ccccc21</smiles>

27

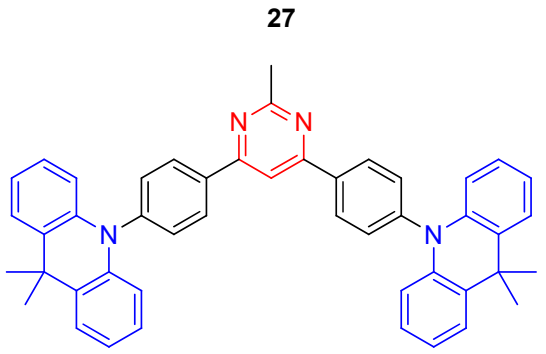

28

\subsection{4 氮杂环并菲类 D-A 型 TADF 蓝光材料}

苯并菲是一类含有四个稠苯环的芳香化合物, 其衍 生物被广泛用于研究设计苂光发光材料 ${ }^{[43]}$, OLED 器件 的主体材料 ${ }^{[44]}$ 、空穴传输材料 ${ }^{[45]}$ 以及电子传输材料 ${ }^{[46]}$, 而 1,4-二氮杂苯并菲衍生物(ATP)含有三个稠苯环和一 个二氮杂环, 由于二氮杂环是一个缺电子单元, $1,4-二$ 氮杂苯并菲衍生物存在较大的 $\pi$ 电子共轭框架, 并具有 良好的电荷传输能力以及相对较高的三重态能级 (约 为 $2.9 \mathrm{eV}$ ), 被广泛应用于研究设计蓝光热活化延迟苂 光材料及 OLED 器件 ${ }^{[43]}$. 如 2014 年, Takahashi 等 ${ }^{[47]}$ 报 道了一系列以 $1,4-$ 二氮杂苯并菲单元为电子受体的天蓝 色蓝光 TADF 分子及其 OLED 器件 29 31. 由于电子受 体与给体之间存在较大的空间位阻作用, 使三个分子均 能获得足够小的 $\Delta E_{\mathrm{ST}}$ 值, 从而表现出明显的热活化延 迟苂光效应. 三种 TADF 材料的甲苯溶液在无氧处理 (氮气鼓泡)后可以抑制 TADF 分子激发态能量转移至三 线态氧中, 使其表现出更低的 $\Delta E_{\mathrm{ST}}$ 值 (氮气鼓泡前为 $0.28,0.25$ 以及 $0.50 \mathrm{eV}$, 氮气鼓泡后为 $0.16,0.13$ 以及 $0.26 \mathrm{eV}$ ). 基于三种分子设计的 OLED 器件结构为 ITO/ $\alpha-\mathrm{NPD} / \mathrm{mCP} / \mathbf{2 9} \sim 31(6 \mathrm{wt} \%): \alpha-\mathrm{NPD}(15 \mathrm{~nm}) / \mathrm{PPT}(10$ $\mathrm{nm}) / \mathrm{TPBi}(40 \mathrm{~nm}) / \mathrm{LiF}(0.8 \mathrm{~nm}) / \mathrm{Al}(70 \mathrm{~nm})$, 获得了器件 最大 $\mathrm{EQE}$ 分别为 $7.5 \%, 8.7 \%$ 以及 $7.5 \%$.
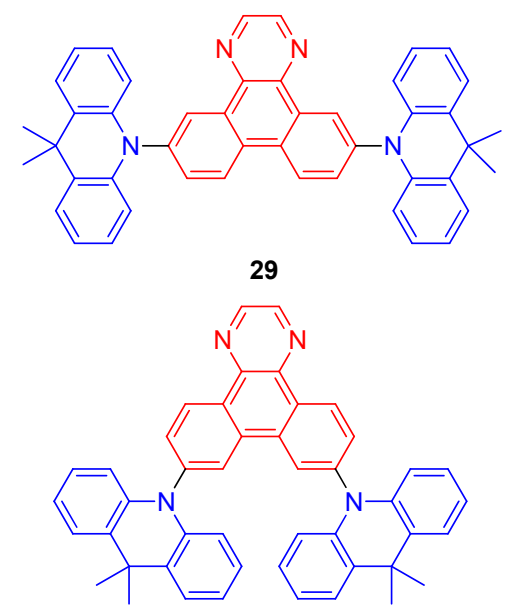

30<smiles>c1ccc(N(c2ccccc2)c2ccc3c4cc(-n5c6ccccc6c6ccc(-n7c8ccccc8c8cc(N(c9ccccc9)c9ccccc9)ccc87)cc65)ccc4c4nccnc4c3c2)cc1</smiles>

2016 年, $\mathrm{Li}$ 等 ${ }^{[37 a]}$ 报道了两种 D-A 型深蓝色 TADF 分子 32 和 33, 分别以 1,2,4-三唑和菲并咪唑作为电子给 受体单元. 在四氢呋喃溶液中, 两者的发射波长分别为 428 和 $420 \mathrm{~nm}$, 并表现出较高的 PLQY $(75 \% \pm 2 \%$ 以及 $43 \%$ ). 基于两种分子设计的的非掺杂的 OLED 器件表<smiles>c1ccc(N(c2ccccc2)c2ccc(-c3nnc(-c4ccc(N(c5ccccc5)c5ccccc5)cc4)n3-c3ccc(-n4c5ccccc5c5ccccc54)cc3)cc2)cc1</smiles>

32

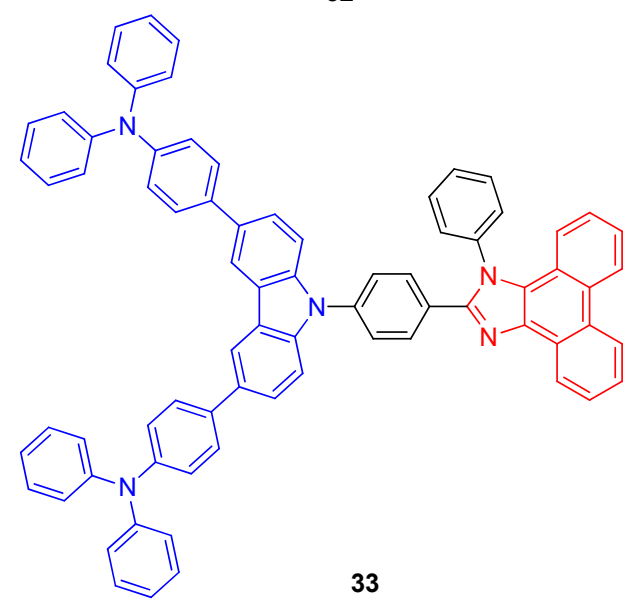


现出极佳的 CIE 坐标, $(0.158,0.043)$ 以及 $(0.156,0.058)$.

基于 33 结构为 $\mathrm{ITO} / \mathrm{MoO}_{3}(6 \mathrm{~nm}) / \alpha-\mathrm{NPD}(35 \mathrm{~nm}) / 33(25$ $\mathrm{nm}) / \mathrm{TPBi}(55 \mathrm{~nm}) / \mathrm{LiF}(0.8 \mathrm{~nm}) / \mathrm{Al}(100 \mathrm{~nm})$ 的器件最大 EQE 为 $6.8 \%$. 器件表现出较低的效率滚降现象, 在 $1000 \mathrm{~cd} \cdot \mathrm{m}^{-2}$ 亮度下仍保持最大 $\mathrm{EQE}$ 的 $79 \%$; 即使在 $7323 \mathrm{~cd} \cdot \mathrm{m}^{-2}$ 最大亮度下仍然保持最大 $\mathrm{EQE}$ 的 $66 \%$, 是 目前已报道的 $\operatorname{CIE}(y)<0.06$ 的非掺杂发光器件中 $\mathrm{EQE}$ 较高者. 而基于 32 结构为 $\mathrm{ITO} / \mathrm{MoO}_{3}(5 \mathrm{~nm}) / 32(55 \mathrm{~nm}) /$ $\mathrm{TPBi}(55 \mathrm{~nm}) / \mathrm{LiF}(0.5 \mathrm{~nm}) / \mathrm{Al}(100 \mathrm{~nm})$ 的最大 EQE 只有
$3.5 \%$.

对上述四类含氮杂环及其衍生物作为电子受体的 D-A 型蓝光 TADF 材料进行总结, 发现在氮杂环相似位 点引入相同结构和数量的电子给体时(如表 2 所示, 分 别以 2,4,6-三苯基-1,3,5-三嗪、2,5-二苯基-1,3,4-噁二唑、 3,4,5-三苯基-1,2,4-三唑、2,4,6-三苯基嘧啶以及 1,4-二氮 杂苯并菲作为电子受体, 均连接两个吩啞嗪电子给体), 由于 $1,3,5$-三嗪和嘧啶单元具有更好的吸电子能力、更

表 2 四种典型氮杂环电子受体 D-A 型 TADF 分子在溶液中光致发光波长 $\left(\lambda_{\mathrm{PL}}\right)$ 、绝对苂光量子产率(PLQY, 氮气环境下)及单重 态一三重态能级差 $\left(\Delta E_{\mathrm{ST}}\right)$

Table 2 PL peak $\left(\lambda_{\mathrm{PL}}\right)$ in solution, absolute photoluminescence quantum yield (PLQY, under nitrogen) and singlet-triplet energy gap $\left(\Delta E_{\mathrm{ST}}\right)$ for 4 typical nitrogen heterocycle-based D-Atype TADF emitters

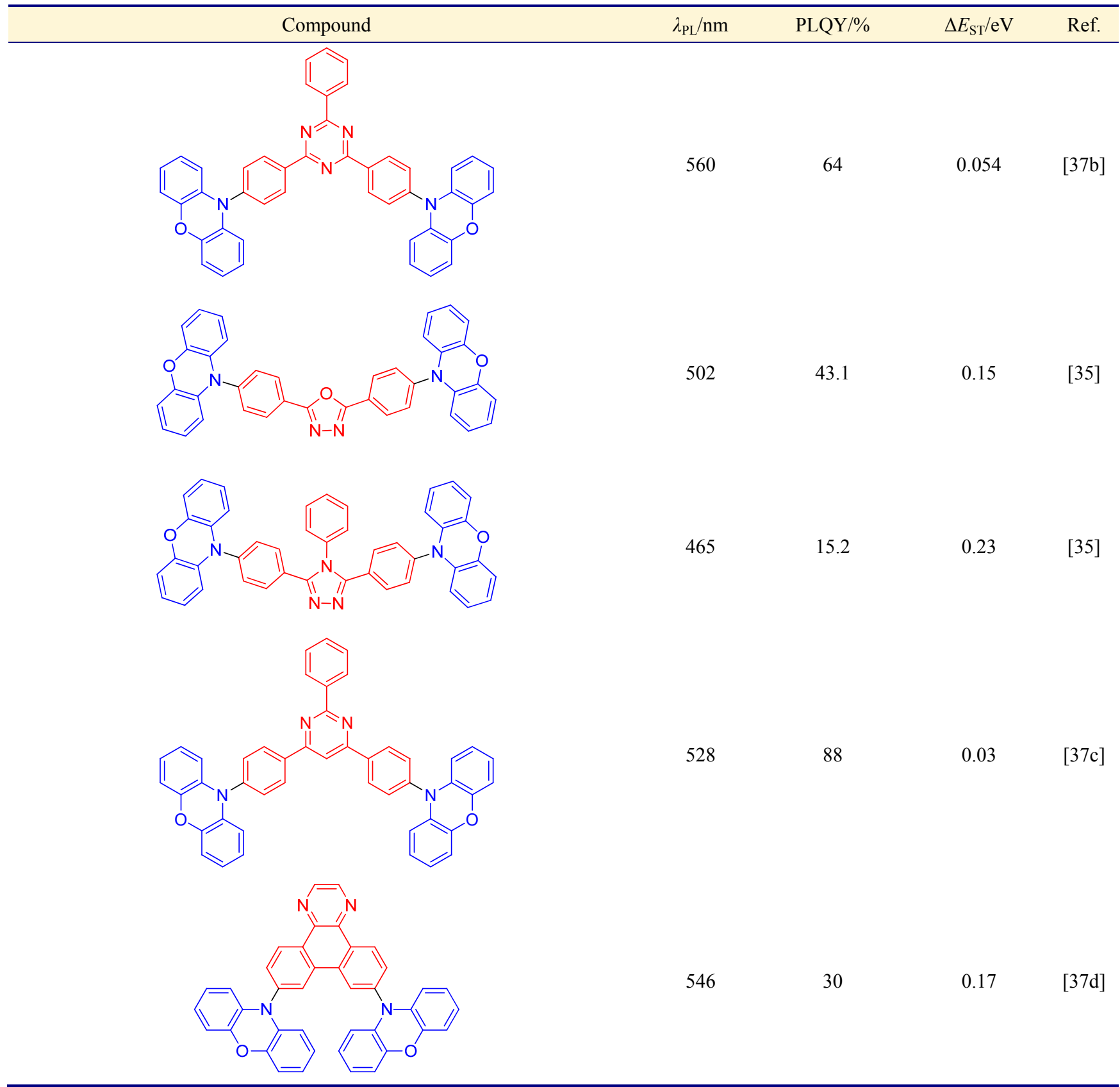


容易引起大的空间位阻, 所以以其作电子受体构建 D-A 型 TADF 分子时更容易获得较低的 $\Delta E_{\mathrm{ST}}$ 值, 其 RISC 过 程越高效, 获得更高的 PLQY; 而 1,4-二氮杂苯并菲、啞 二唑和三唑单元由于其相对较弱的吸电子能力或较小 的空间体积, 构建 D-A 型 TADF 分子时获得的 $\Delta E_{\mathrm{ST}}$ 值 相对较大, 相对不利于获得较高的 PLQY. 另一方面, 三嗪和嘧啶单元作为电子受体构建 TADF 分子时, 其发 光波长往往长于以 1,4 -二氮杂苯并菲、啞二唑和三唑单 元作为电子受体的 TADF 分子, 在构建深蓝光 D-A 型 $\mathrm{TADF}$ 材料方面存在一定的劣势. 当氮杂环电子受体连 接其他电子给体时, 亦能得出同样的规律 ${ }^{[48,49]}$.

\section{2 二苯甲酮类 D-A 型 TADF 蓝光材料}

由于二苯甲酮衍生物含有缺电子的羰基 $(\mathrm{C}=\mathrm{O})$, 作 为电子受体时羰基与苯环存在较大的扭转角, 是一种系 间窝越十分高效 $\left(k_{\mathrm{ISC}}=10^{11} \mathrm{~s}^{-1}\right)$ 的纯有机磷光体, 十分 适合用作为电子受体构建 D-A 型 TADF 蓝光分子. 2013 年, Adachi 等 ${ }^{[50]}$ 设计合成了首个以鲐定单元为电子给体, 蒽酮为电子受体的螺衍生物蓝光 TADF 分子 34 . 具有十 分低的 $\Delta E_{\mathrm{ST}}$ 值 $(0.03 \mathrm{eV})$ 的同时, 该分子在 $300 \mathrm{~K}$ 下表现 出即时苂光和延迟苂光现象, 两者寿命为 $175 \mathrm{~ns}$ 和 5.3 $\mathrm{ms}$. 在固体状态下具有很高的 PLQY (81\%), 以 ITO/ $\alpha$-NPD (40 nm)/mCP (10 nm)/34 (20 wt\%):DPEPO (15 $\mathrm{nm}) / \mathrm{DPEPO}(3.5 \mathrm{~nm}) / \mathrm{TPBi}(41.5 \mathrm{~nm}) / \mathrm{LiF}(0.8 \mathrm{~nm}) / \mathrm{Al}(80$ $\mathrm{nm})$ 结构构成的 OLED 器件的最大 EQE 达到 $16.5 \%$.

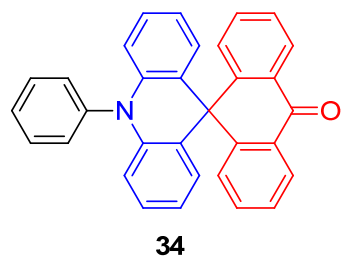

次年，该团队 ${ }^{[18]}$ 又报道了一系列以二苯甲酮为电 子受体, 以吩噁嗪、咔唑衍生物作为电子给体的 D-A-D “蝴蝶型” TADF 分子 35 39. 经含时密度泛函理论计算, 这些分子的基态几何图形中二苯甲酮单元的苯环和电 子给体单元之间存在较大的二面角 $\left(35\right.$ 为 $51^{\circ} 、 36$ 为 $61^{\circ}$ 以及 37 为 $\left.85^{\circ}\right)$, 使分子获得很小的 $\Delta E_{\mathrm{ST}}$ 值 $(0.03 \sim 0.21$ eV). 5 种分子在无氧甲苯溶液中的苂光光谱显示, PLQY 为 $10 \% \sim 44 \%$, 含有单个苯甲酰基团的 35 37 三种分子 的发光波长分别在 438,462 以及 $509 \mathrm{~nm}$, 而含两个苯甲 酰基团的 38 和 39 分子的苂光发射峰发生红移(发射波 长为 566 和 $600 \mathrm{~nm}$ ), 发射绿光以及橙色光, 这是因为外 加的高电负性苯甲酰基能够使带隙能量降低, 从而使 LUMO 变得更加稳定. 质量分数为 $6 \%$ 的 TADF 材料掺 杂在 DPEPO 主体成膜时即时苂光寿命和延迟苂光寿命 分别为 35 (59 ns, $710 \mathrm{~ms}), \mathbf{3 6}$ (62 ns, $460 \mathrm{~ms}), 37$ (23 ns,
$12 \mathrm{~ms}), \mathbf{3 8}(24 \mathrm{~ns}, 13 \mathrm{~ms})$ 和 39 (26 ns, $2.9 \mathrm{~ms})$. 为了研究 35 37 三种蓝光 TADF 分子的器件特性, 将 36 和 37 掺 杂在 DPEPO 中, 构成结构为 ITO $/ \alpha-\mathrm{NPD}(35 \mathrm{~nm}) / \mathrm{mCP}$ $(5 \mathrm{~nm}) / 35$ 或 36 (6 wt \%):DPEPO (20 nm)/DPEPO (10 $\mathrm{nm}) / \mathrm{TPBi}(30 \mathrm{~nm}) / \mathrm{LiF}(0.8 \mathrm{~nm}) / \mathrm{Al}(80 \mathrm{~nm})$ 的 OLED 器件, 分别获得最大 $E Q E$ 为 $8.1 \%$ 和 $14.3 \% ; 37$ 则掺杂在 $\mathrm{mCBP}$ 中构成 ITO $/ \alpha-\mathrm{NPD}(40 \mathrm{~nm}) / 37$ (6 wt \%):mCBP $(20$ $\mathrm{nm}) / \mathrm{TPBi}(40 \mathrm{~nm}) / \mathrm{LiF}(0.8 \mathrm{~nm}) / \mathrm{Al}(80 \mathrm{~nm})$ 的 OLED 器件, 最大 $\mathrm{EQE}$ 为 $10.7 \% .3$ 种蓝光 $\mathrm{TADF}$ 分子中, 36 的上转换 效果最好, 获得最多的三重态激子, 故其器件最大 EQE 最高, 且能发射较纯蓝色光, CIE 色坐标为 $(0.17,0.27)$.
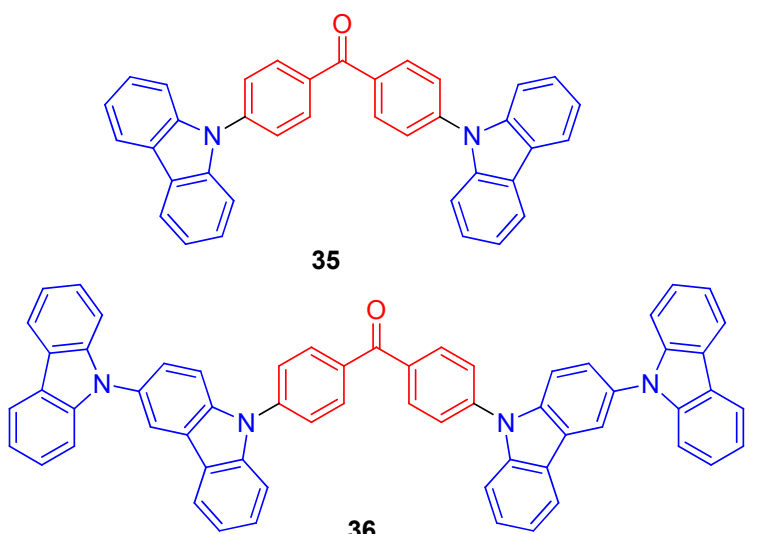

36<smiles>O=C(c1ccc(N2c3ccccc3Oc3ccccc32)cc1)c1ccc(N2c3ccccc3Oc3ccccc32)cc1</smiles>

37<smiles>O=C(c1ccc(N2c3ccccc3Oc3ccccc32)cc1)c1cccc(C(=O)c2ccc(N3c4ccccc4Oc4ccccc43)cc2)c1</smiles>

38

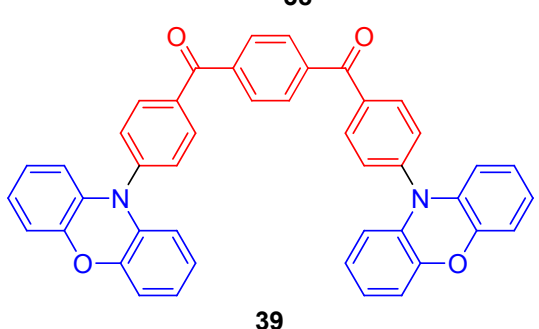

39

随后，该团队 ${ }^{[19]}$ 继续以苯甲酰基-二苯甲酮为电子 受体, 9,9-二甲基呋啶为电子给体合成了一种 “ $X$ 型” 蓝 光 $\mathrm{TADF}$ 分子 $\mathbf{4 0}$ (在无氧甲苯溶液中最大发射波长为 $496 \mathrm{~nm}$ 发射蓝色光). 苯甲酰基-二苯甲酮较大的空间体 积与 9,9-二甲基浐啶单元形成较大的空间位阻作用，使 
该分子的 $\Delta E_{\mathrm{ST}}$ 值仅为 $0.02 \mathrm{eV}$, 使得 40 即使在室温环境 也能快速完成 RISC 过程, 以获得更好的热活化延迟苂 光. 经测试, 该分子在无氧甲苯溶液中 PLQY 为 $20 \%$ 左 右, 但掺杂在 $\mathrm{mCBP}$ 薄膜中则升高为 $46 \%$, 表明固体状 态时由于分子内激子旋转被限制, 非辐射激子的猝灭被 抑制. 其 OLED 结构为 ITO $/ \alpha-\mathrm{NPD}(35 \mathrm{~nm}) / \mathrm{mCP}(10$ $\mathrm{nm}) / \mathbf{4 0}(6 \mathrm{wt} \%)$ :mCBP $(20 \mathrm{~nm}) / \mathrm{PPF}(10 \mathrm{~nm}) / \mathrm{TPBi}(30$ $\mathrm{nm}) / \mathrm{LiF}(0.8 \mathrm{~nm}) / \mathrm{Al}(80 \mathrm{~nm})$, 最大 $\mathrm{EQE}$ 为 $10.0 \%$. 但器 件在高电流密度工作状态下 $\left(100 \mathrm{~mA} \cdot \mathrm{cm}^{-2}\right.$ 以上 $)$ 表现出 较明显的效率滚降，最大 $\mathrm{EQE}$ 下降至 3\%以下.

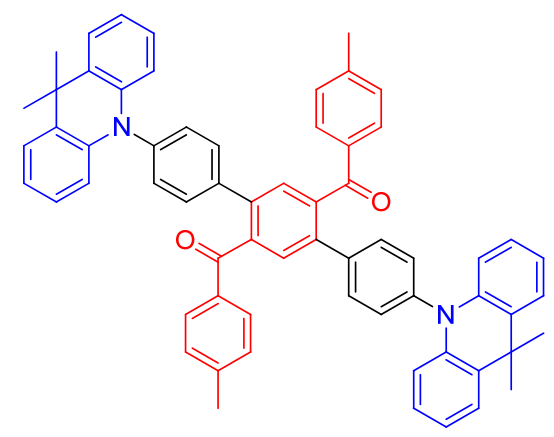

40

2016 年, Lee 等 ${ }^{[30]}$ 借鉴 “蝴蝶型” TADF 分子 $\mathbf{3 5}$ 的 思路, 通过在二咔唑电子给体上添加苯环, 扩大分子的 空间位阻合成一种新的蓝光 TADF 分子 41. 同样获得较 小的 $\Delta E_{\mathrm{ST}}(0.16 \mathrm{eV})$, 结构为 ITO $(120 \mathrm{~nm}) / \mathrm{PEDOT}$ :PSS $(60 \mathrm{~nm}) /$ TAPC $(20 \mathrm{~nm}) / \mathbf{4 1}$ :DPEPO $(25 \mathrm{~nm}) /$ TSPO1 (5 $\mathrm{nm}) / \mathrm{TPBi}(30 \mathrm{~nm}) / \mathrm{LiF}(1.5 \mathrm{~nm}) / \mathrm{Al}(200 \mathrm{~nm})$ 的 OLED 器 件甚至获得了高达 $23.3 \%$ 的最大 $\mathrm{EQE}$ ，高于 35 的 $14.3 \%$.

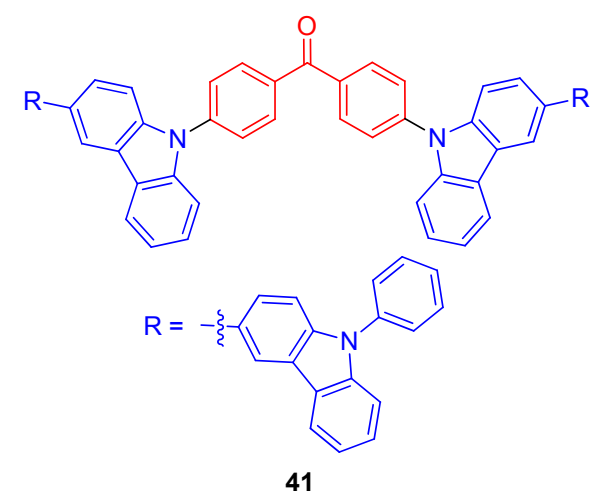

2016 年末, Kim 等 ${ }^{[51]}$ 报道了一种以二苯甲酮作为电 子受体, 以 azasiline 衍生物作为电子给体的蓝光 TADF 分子 42. 以 mCP:TSPO1:45 (16 wt \%)掺杂成膜测试得的 $\Delta E_{\mathrm{ST}}$ 值为 $0.06 \mathrm{eV}$, 成膜时的 PLQY 达到 $70 \%$. 分子在甲 苯溶液以及薄膜形式中测得的最大发射波长均为 468 $\mathrm{nm}$ 左右, 但以 ITO $(70 \mathrm{~nm}) / \mathrm{ReO}_{3}(4 \mathrm{wt} \%): \mathrm{mCP}(45 \mathrm{~nm}) /$
$\mathrm{mCP}(15 \mathrm{~nm}) / \mathrm{mCP}: \mathrm{TSPO} 1: 42(15 \mathrm{~nm}) / \mathrm{TSPO} 1(15 \mathrm{~nm}) /$ $\mathrm{Rb}_{2} \mathrm{CO}_{3}(4 \mathrm{wt} \%)$ :TSPO1 $(50 \mathrm{~nm}) / \mathrm{Al}(100 \mathrm{~nm})$ 为结构制 作 OLED 器件时, 由于器件存在空穴效应导致其发射波 长红移至 $484 \mathrm{~nm}$, 显示天蓝色, CIE 色坐标为 $(0.174$, 0.310 ), 最大 $\mathrm{EQE}$ 为 $11.4 \%$. 器件的启动电压仅为 $3.6 \mathrm{~V}$, 在此前报道的 TADF 型 OLED 器件中为较低者.

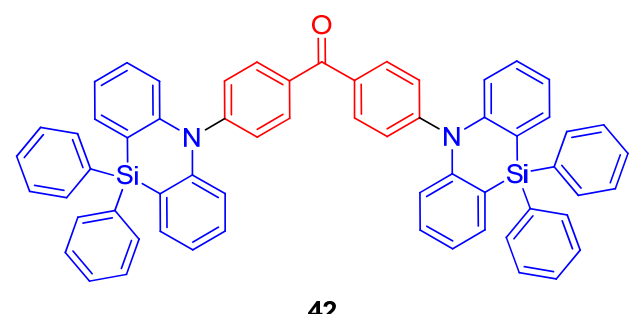

2016 年, Cheng 等 ${ }^{[52]}$ 报道了两种结构相似, 均以苯 甲酰基吡啶单元为电子受体，咔唑/3,6-二叔丁基咔唑为 电子给体的 $\mathrm{TADF}$ 分子 $\mathbf{4 3}$ 和 $\mathbf{4 4}$, 由于分子内电子给体 和受体之间存在强的空间相互作用, 使两种分子获得很 低的 $\Delta E_{\mathrm{ST}}$ 值 $(0.03$ 和 $0.04 \mathrm{eV})$. 同时, 43 和 44 分别掺杂 在 $\mathrm{CzPS}$ 以及 CBP 薄膜中均表现出很高的 PLQY $(88.0 \%$, $91.4 \%$ ). 43 在甲苯溶液中发射波长为 $490 \mathrm{~nm}$ 发射蓝色 光，而 44 由于电子给体单元上连接了叔丁基，导致其发 光波长发生红移(508 $\mathrm{nm}$ )发射绿色光. 基于 43 并以 $\mathrm{CzPS}$ 为主体材料的 OLED 结构为 ITO/ $\alpha-\mathrm{NPD}(30 \mathrm{~nm}) /$ $\mathrm{mCP}(20 \mathrm{~nm}) / \mathrm{CzPS}: 43$ (5 wt\%, $30 \mathrm{~nm}) / \mathrm{DPEPO}(5 \mathrm{~nm}) /$ $\mathrm{TmPyPb}(60 \mathrm{~nm}) / \mathrm{LiF}(1 \mathrm{~nm}) / \mathrm{Al}(100 \mathrm{~nm})$, 获得较高的最 大 EQE (24.0\%), 并且表现出较低的效率滚降效应. 由 于分子 43 相当小的 $\Delta E_{\mathrm{ST}}$ 值抑制了材料的非辐射衰变, 其 OLED 器件在较高的亮度下仍然保持较高水平.
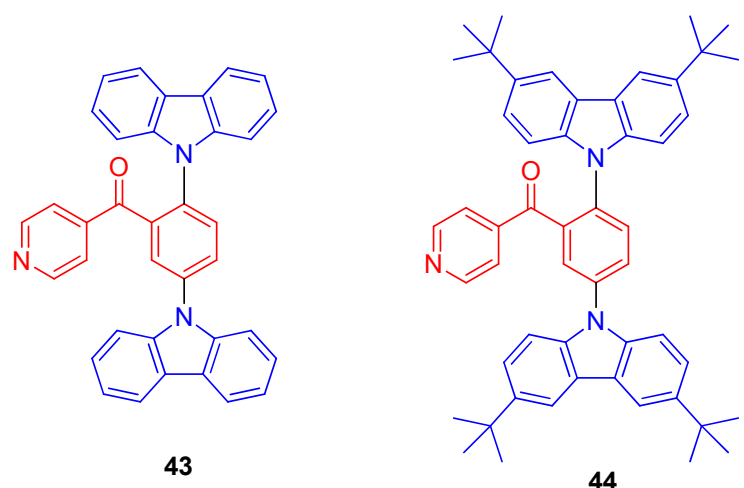

次年, 该团队 ${ }^{[53]}$ 在 2016 年的研究成果基础上, 继 续合成了一个与 $\mathbf{4 3}$ 互为同分异构体新的蓝光 TADF 分 子 45. 在甲苯溶液中, 45 的 $\Delta E_{\mathrm{ST}}$ 为 $0.06 \mathrm{eV}$. 苂光光谱表 明其发射峰在 $467 \mathrm{~nm}$ 发射蓝色光. 值得一提的是, 45 在 晶体形式和无定型态时发射波长从 $460 \mathrm{~nm}$ 发射蓝色光 变为 $510 \mathrm{~nm}$ 发射绿色光. 更有趣的是, 其 PLQY 也从 
$55 \%$ 提高到 $82 \%$. 以 ITO $/ \alpha-\mathrm{NPD}(40 \mathrm{~nm}) / \mathrm{mCP}(10 \mathrm{~nm}) /$ DPEPO:45 (10 30 wt\%, $30 \mathrm{~nm}) / \mathrm{PPT}(5 \mathrm{~nm}) / \mathrm{TmPyPb}(60$ $\mathrm{nm}) / \mathrm{LiF}(1 \mathrm{~nm}) / \mathrm{Al}(100 \mathrm{~nm})$ 为结构的 OLED 获得 $18.4 \%$ 的最大 $\mathrm{EQE}$, 并且发现随着质量分数减少(从 $30 \%$ 到 $10 \%$ ), 器件的 EQE 逐渐增加.

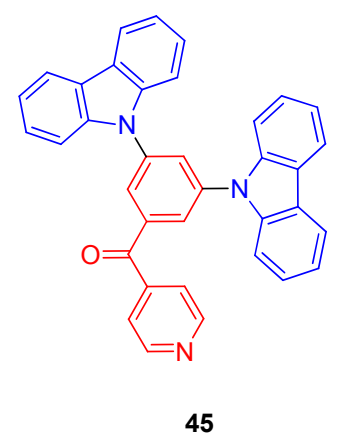

\section{3 含氪基的 D-A 型 TADF 蓝光材料}

氭基具有十分强的吸电子能力, 成为构建低 $\Delta E_{\mathrm{ST}}$, 高 $k_{\mathrm{r}}$ 的 D-A 型 TADF 分子的常用电子受体. 2012 年, Adachi 等 ${ }^{[15]}$ 合成了一系列咔唑基-苯二腈基 TADF 分子. 这些分子中咔唑平面与苯二腈单元平面之间存在较大 的扭曲二面角, 使其获得较低的 $\Delta E_{\mathrm{ST}}$. 该团队通过调整 咔坐电子给体的数量和其与氰基的相对位置, 获得不同 光学性能(从蓝色光到橙色光)的 TADF 分子. 其中只有 分子 46 发射蓝光(在甲苯溶液中发射波长为 $473 \mathrm{~nm}$ ), $\Delta E_{\mathrm{ST}}$ 为 $0.34 \mathrm{eV}$. 在无氧(氮气鼓泡)的甲苯溶液中测试其 PLQY 为 $46.5 \%$. 构建结构为 ITO $(100 \mathrm{~nm}) / \alpha$-NPD (40 $\mathrm{nm}) / \mathrm{mCP}(10 \mathrm{~nm}) / \mathrm{PPT}: 46$ (5 wt $\%, 20 \mathrm{~nm}) / \mathrm{PPT}(40 \mathrm{~nm}) /$ $\mathrm{LiF} / \mathrm{Al}$ 的 OLED 器件, 其中 PPT 为主体材料的 OLED 器 件获得了 $8 \%$ 的最大 EQE, 大于传统荧光 OLED 的最大 EQE $(5 \%)$. 但该器件在高电流密度工作状态下表现出 较大的 EQE 效率滚降的现象. 2013 年 Adachi 团队 ${ }^{[54]}$ 通 过建立理论模型探究了 46 的效率滚降原因, 构建的器 件在低电流密度 $\left(J=0.01 \mathrm{~mA} \cdot \mathrm{cm}^{-2}\right)$ 时获得最高 $\mathrm{EQE}$ 值 $(13.6 \% \pm 1 \%)$, 其原因是该电流密度工作状态下存在高 效的载流子复合和发光层激子约束. 然而随着电流密度 的升高, 其 $\mathrm{EQE}$ 值逐渐下降, 在高电流密度状态 $(J=10$ $\left.\mathrm{mA} \cdot \mathrm{cm}^{-2}\right)$ 下, 其最大 $\mathrm{EQE}$ 值只有 $3.6 \% \pm 1 \%$, 原因为高 电流密度导致激子猝灭.

为了提高以化合物 46 作为发光层的的 OLED 器件 性能, 2016 年 Sun 等 ${ }^{[55]}$ 利用 $\mathrm{mCP}$ 为空穴传输层、PO-15 为电子传输层并以质量比 $1: 1$ 的方式混合作为器件主 体材料, 构建了基于 46 结构为 $\mathrm{ITO} / \mathrm{ReO}_{3}: \mathrm{mCP} / \mathrm{mCP}: \mathrm{PO}-$ $15: 46(5 \mathrm{wt} \%) / \mathrm{Rb}_{2} \mathrm{CO}_{3}: \mathrm{PO}-15 / \mathrm{Al}$ 的 OLED 器件, 器件获 得了更高的最大 $\mathrm{EQE}$ 值(21.8\%).

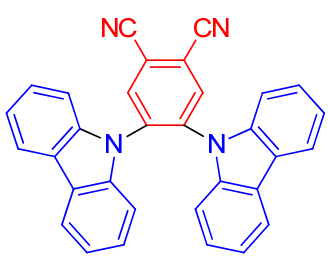

46

2014 年 Lee 等 $^{[56]}$ 设计了一种与 46 互为同分异构体 的蓝光 TADF 分子 $\mathbf{4 7}$. 但与 $\mathbf{4 6}$ 相比, 由于后者两个电子 给体(咔唑基)与两个电子受体(氰基)之间为邻位取代, 在空间上两者相互的阻碍作用更为显著，所以 47 获得 了更低的 $\Delta E_{\mathrm{ST}}$ 值 $(0.05 \mathrm{eV})$. 但由于电子给体和受体之间 的电子转移性质较 46 弱, 所以, 47 在聚氯乙烯中发射波 长蓝移(447 nm). 通过积分球测量发现，47 在甲苯溶液 中 PLQY 为 $35 \%$, 而在掺杂在 $\mathrm{mPC}$ 主体中提升为 $87 \%$. 结构为 ITO (150 nm)/PEDOT:PSS (60 nm)/TAPC (20 $\mathrm{nm}) / \mathrm{mCP}(10 \mathrm{~nm}) / \mathrm{mCP}: 47$ (15 wt\%, $25 \mathrm{~nm}) / \mathrm{TSPO} 1$ (35 $\mathrm{nm}) / \mathrm{LiF}(1 \mathrm{~nm}) / \mathrm{Al}(200 \mathrm{~nm})$ 的 OLED 器件, 获得了 $16.4 \%$ 的最大 EQE. 有趣的是, 当利用 47 作为黄色磷光 器件的主体材料时, 器件获得了高达 $24.9 \%$ 的最大 EQE 值; 而当 47 同时作为蓝色发光材料和黄色磷光主体并 且掺杂设计成 OLED 器件时, 获得了最大 $\mathrm{EQE}$ 为 $22.9 \%, \mathrm{CIE}$ 色坐标为 $(0.39,0.43)$ 的暖色白光 OLED; 以 及最大 $\mathrm{EQE}$ 为 $21.0 \%, \mathrm{CIE}$ 色坐标为 $(0.31,0.33)$ 的冷光白 光 OLED.

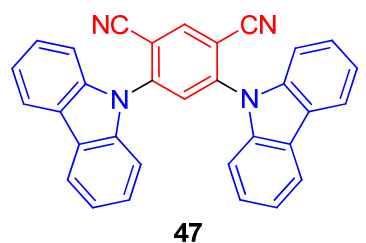

2015 年，该团队 ${ }^{[57]}$ 同样在 46 的基础上，以苯并呋 喃咔唑和苯并噻吩咔唑代替咔唑作为电子给体了合成 两种新型 $\mathrm{D}-\mathrm{A}$ 型蓝光 TADF 分子 48 和 49 . 替换后的两 种较大电子给体基团由于与电子受体之间存在更强的 空间阻碍作用, 两种分子的 $\Delta E_{\mathrm{ST}}$ 值比 46 更低(分别为 0.13 和 $0.17 \mathrm{eV})$, 并且光电性能更加优异. 在无氧(氮气 鼓泡)甲苯溶液中, 48 和 49 分别表现出 94.6\%和 94.0\% 的苂光量子产率，掺杂在 $\mathrm{mCP}$ 薄膜中为 $85 \%$. 基于这两 种分子设计结构为 ITO $(50 \mathrm{~nm}) / \mathrm{PEDOT}$ :PSS $(60$ $\mathrm{nm}) / \mathrm{TAPC}(20 \mathrm{~nm}) / \mathrm{mCP}(10 \mathrm{~nm}) / \mathrm{mCP}: 48$ 或 49 (25 nm, 1 $\mathrm{wt} \%) / \mathrm{TSPO} 1(35 \mathrm{~nm}) / \mathrm{LiF}(1 \mathrm{~nm}) / \mathrm{Al}(200 \mathrm{~nm})$ 的 OLED 器件最大 $\mathrm{EQE}$ 分别为 $12.1 \%$ 和 $11.8 \%$, 均比基于 46 设 计的 OLED 器件高. 


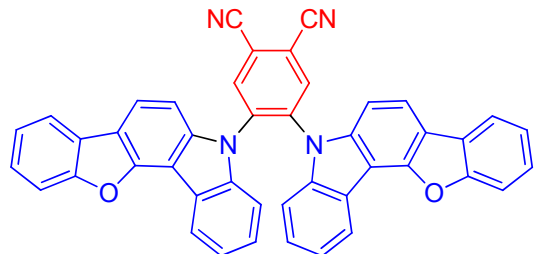

48

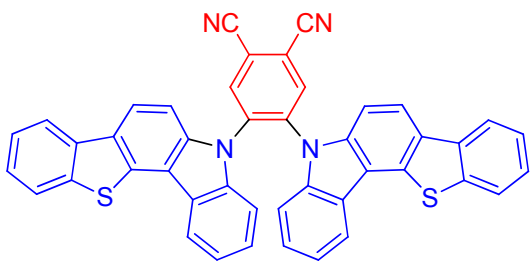

49

随后, Lee 等 ${ }^{[58]}$ 通过 47 分子自身的咔唑电子给体基 才之间以不同位点进行连接, 形成三种 “双胞胎” 式的 $\mathrm{TADF}$ 分子 50 52. 利用这种方法, 通过改变咔唑基团 之间的连接方式, 既可以保留 47 原始的发光颜色, 也可 以调节其发光波长, 以获得绿色和蓝色光的 TADF 发光 分子(发光波长分别为 470,448 以及 $444 \mathrm{~nm}$ ), 并且在发 光性能上均有优化. 在获得低 $\Delta E_{\mathrm{ST}}$ 值 $(0.11,0.16$ 以

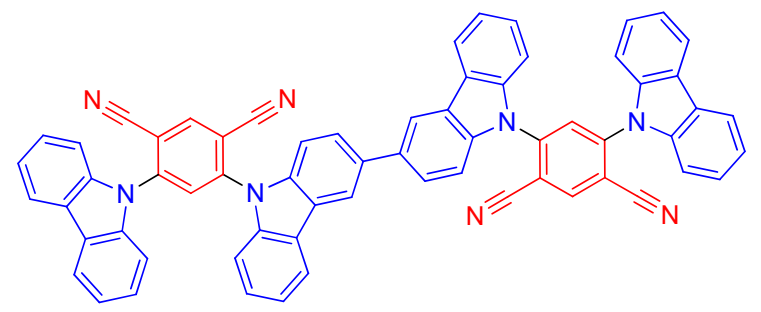

50

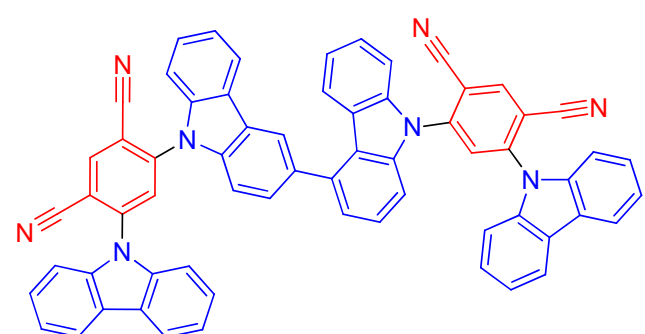

51

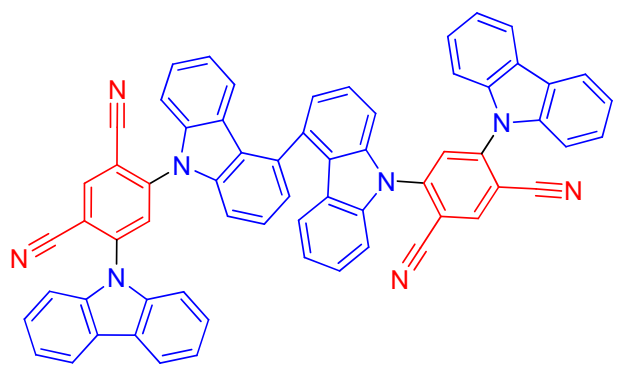

52
及 $0.21 \mathrm{eV})$ 的同时, 获得较高延迟苂光寿命 $(2.35,2.96$ 以及 $4.21 \mathrm{~ms})$ 和较高的苂光量子产率 $(87 \%, 66 \%$ 以及 $61 \%)$. 其中基于蓝光 $\mathrm{TADF}$ 分子的器件 ITO/PEDOT: PSS (60 nm)/TAPC (10 nm)/TCTA (10 nm)/mCP (10 nm)/ DPEPO:51 或 52 (20 wt \%, $25 \mathrm{~nm}) / \mathrm{TSPO} 1$ (5 nm)/TPBi $(35 \mathrm{~nm}) / \mathrm{LiF} / \mathrm{Al})$ 获得较高的器件最大 EQE (21.8\% 和 $19.5 \%)$, 且表现出较纯色的蓝色光, CIE 色坐标分别为 $(0.17,0.29)$ 和 $(0.16,0.23)$.

Lee 等 ${ }^{[59]}$ 在获得以上一系列以苯腈单元作为电子受 体, 咔唑为电子给体的蓝光 TADF 分子的基础上, 进一 步通过引入同样为吸电子的氟基团以增加材料的溶解 性，获得了一系列能用于旋涂成膜的蓝光发光材料 53 和 54. 由于咔唑基团与氰苯基团较大的空间阻碍作用, 53 和 54 均获得很小的 $\Delta E_{\mathrm{ST}}$ 值 (均为 $0.06 \mathrm{eV}$ ). 两者在无 氧(氮气鼓泡)的甲苯溶液中发射波长分别为 443 和 453 $\mathrm{nm}$. 由于以相对较弱吸电子能力的 $\mathrm{F}$ 原子取代具有相 对较强吸电子能力的 $\mathrm{CN}$ 基团, 53 和 54 的发射波长均比 含两个 $\mathrm{CN}$ 基团的 $\mathbf{4 6}^{[46]}$ 的发射波长短. 延迟荣光寿命分 别为 28 和 $17 \mathrm{~ms}$, PLQY 分别为 $76 \%$ 和 $81 \%$. 两种分子 掺杂在 $\mathrm{SiCz}$ 中，用旋涂成膜的方式构成结构为 ITO/PEDOT:PSS (60 nm)/PVC (15 nm)/SiCz:53 或 54 (15 $\mathrm{wt} \%, 20 \mathrm{~nm}) / \mathrm{EMPA} 1(5 \mathrm{~nm}) / \mathrm{TPBi}(30 \mathrm{~nm}) / \mathrm{LiF}(1 \mathrm{~nm}) / \mathrm{Al}$ $(200 \mathrm{~nm}$ ) 的 OLED 器件获得 $17.8 \%$ 和 $20.0 \%$ 的最大 EQE, 且发光为较纯的蓝色光, CIE 色坐标为 $(0.16,0.19)$ 和 $(0.16,0.25)$. 另外, 用真空热蒸镀的方式制作发光层的 OLED 器件获得的最大 EQE 仅为 $12.9 \%$ 和 $17.3 \%$. 因此 通过引入氟原子基团的 TADF 材料用以旋涂成膜，可以 提高 OLED 器件的 EQE.

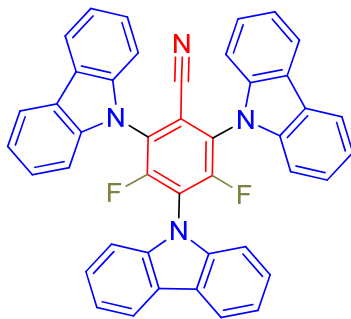

53

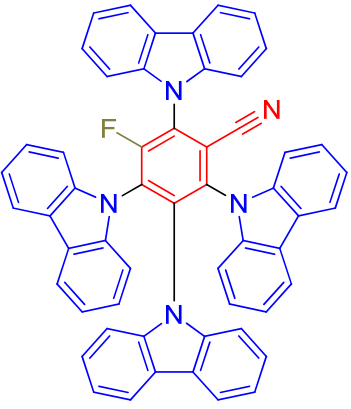

54
2016 年，由该团队 ${ }^{[60]}$ 报道了一种以咔唑为电子给 体，氰基苯为电子受体的 “联锁式” 蓝光 TADF 分子 $\mathbf{5 5}$. 由于在两个苯环连接的主干线上，2,2'位置上两个空间 体积较大的咔唑基团之间存在空间阻碍作用，故两个苯 环之间连接的 $\sigma$ 键旋转时会受到一定的限制. 而与 55 互为同分异构体 56 的 2,2'位置上为氰基，分子苯环的 $\sigma$ 键旋转时受到的限制相对较小. 两者 $\Delta E_{\mathrm{ST}}$ 值均为较小 
的 $0.27 \mathrm{eV}$, 但 $\mathbf{5 5}$ 表现出更大的振子强度, 为 $0.230(\mathbf{5 6}$ 为 0.193$)$. 因此, 55 的 PLQY 为 $76 \%$, 大于 56 (46\%). 更 重要的是, 苂光光谱显示 $\mathbf{5 5}$ 的光谱图较 $\mathbf{5 6}$ 的荧光光谱 狭窄, 前者的半峰宽度只有 $48 \mathrm{~nm}$ (而后者为 $71 \mathrm{~nm}$ ), 普 遍低于已经报道的蓝光分子的半峰宽, 在制作纯蓝光 OLED 器件上更有优势. 55 和 $\mathbf{5 6}$ 掺杂在 DPEPO 中制成 OLED 器件获得的器件最大 EQE 分别为 $14 \%$ 和 $4.8 \%$, 且由于前者荧光光谱较窄, 器件能发射会较纯的深蓝色 光, CIE 色坐标为 $(0.14,0.12)$.

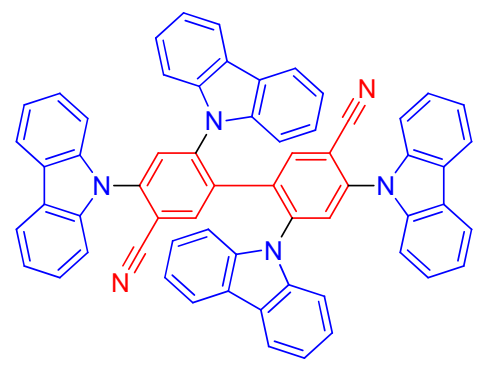

55

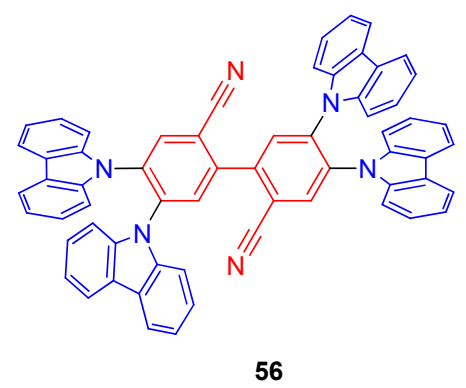

2016 年, Park 等 ${ }^{[61]}$ 报道了两个分别以邻苯二腈作为 电子受体，1-甲基咔唑和 9,9-二甲基叫啶等基团作为电 子给体的楔形蓝光 TADF 分子 $\mathbf{5 7 ,} \mathbf{5 8}$. 二者的 $\Delta E_{\mathrm{ST}}$ 值

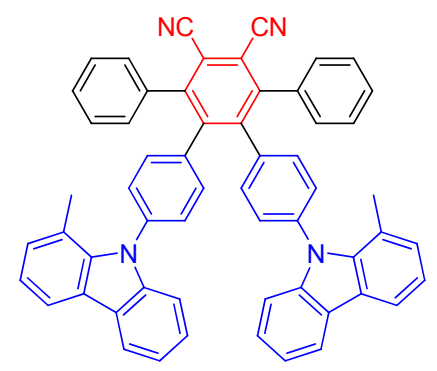

57

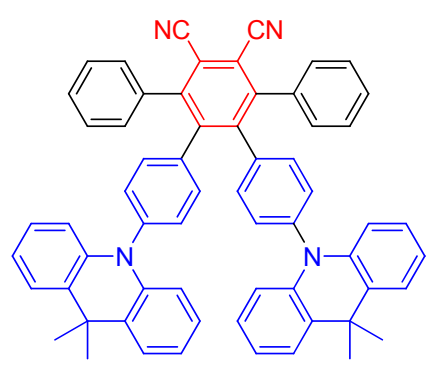

58
分别 0.36 和 $0.20 \mathrm{eV}$ ，掺杂在 PPF (57)或 mCBP (58)中的 薄膜 PLQY 高达 $63 \%$ 和 $86 \%$. 基于二者的 OLED 蓝光器 件结构为 ITO $(110 \mathrm{~nm}) / \alpha-\mathrm{NPD}(40 \mathrm{~nm}) / \mathrm{mCP}(10 \mathrm{~nm}) / 57$ 或 $58(20 \mathrm{~nm}) / \mathrm{PPF}(10 \mathrm{~nm}) / \mathrm{TPBi}(30 \mathrm{~nm}) / \mathrm{LiF} \quad(0.8$ $\mathrm{nm}) / \mathrm{Al}(100 \mathrm{~nm})$, 器件最大 $\mathrm{EQE}$ 分别为 $8.7 \%$ 和 $18.9 \%$. 值得一提的是, $\mathbf{5 8}$ 在亮度 $\left(10000 \mathrm{~cd} \cdot \mathrm{m}^{-2}\right)$ 下仍然保持 $12.4 \%$ 的最大 $\mathrm{EQE}$ ，表现出较低的效率滚降.

Zhang 等 ${ }^{[62]}$ 报道两种以苯腈为电子受体, 吩噁嗪作 为电子给体的蓝光 $\mathrm{TADF}$ 同分异构体分子 $\mathbf{5 9}$ 和 $\mathbf{6 0}$. 由 于具有相同的分子骨架, 二者的茮腈基团和吩噁嗪部分 之间的二面角分别达到近乎垂直的 $75.29^{\circ}$ 和 $78.79^{\circ}$, 使 两种分子都获得相当小的 $\Delta E_{\mathrm{ST}}$ 值(分别为 0.02 和 0.01 $\mathrm{eV}$ ). 掺杂在 $\mathrm{mCP}$ 薄膜中通过积分球测试表明二者也具 有较高的 PLQY, 分别为 $46.6 \%$ 和 $54.9 \%$. 但由于 $\mathbf{5 9}$ 和 60 芐腈单元上连接的苯环取代基位置不同，前者为氰 基的邻位取代，而后者为氰基的间位取代，导致两种分 子在空间上的阻碍作用不同: 60 上两个与吩噁嗪紧靠着 的苯环使芐腈与吩噁嗪之间的 $\sigma$ 键旋转受限, 而 $\mathbf{5 9}$ 的这 种限制 $\sigma$ 键旋转的效应并不明显. 这两种不同的分子空 间作用，使两者的光电性能有所不同. 溶剂从非极性的 环己烷到极性的乙腈，两者均有正溶剂化变色效应：59 的发光波长和半峰宽均分别为 $455 \sim 615 \mathrm{~nm}$ 和 $60 \sim 140$ $\mathrm{nm}$, 而 60 的发光波长和半峰宽分别为 $455 \sim 550 \mathrm{~nm}$ 和 60 107 nm. 表明通过增加分子内的空间限制作用，可 以降低分子的正溶剂化变色效应，同时可以提高分子发 光色纯度(较低的半峰宽). 基于二者的 OLED 器件结构 为 ITO/TAPC $(40 \mathrm{~nm}) / \mathrm{TCTA}(5 \mathrm{~nm}) / \mathrm{mCP}: 6.5 \mathrm{wt} \% 59$ 或 $\mathbf{6 0}(20 \mathrm{~nm}) / \mathrm{TmPyPb}(35 \mathrm{~nm}) / \mathrm{LiF}(1 \mathrm{~nm}) / \mathrm{Al}$, 均获得较高 的器件最大 $\mathrm{EQE}$, 分别为 $(19.9 \%$ 和 $17.4 \%)$. 基于 $\mathbf{6 0}$ 的 OLED 器件获得更高的色纯度, CIE 色坐标 $(0.18,0.32)$.<smiles>N#Cc1c(-c2ccccc2)cc(N2c3ccccc3Oc3ccccc32)cc1-c1ccccc1</smiles><smiles>N#Cc1cc(-c2ccccc2)c(N2c3ccccc3Oc3ccccc32)c(-c2ccccc2)c1</smiles>

60

除了以氧基苯作为电子受体外, 近年来学者亦报道 了一系列以氰基取代含氮杂环衍生物作为电子受体的 蓝光 TADF 分子及 OLED 器件. 2015 年, Liu 等 ${ }^{[63]}$ 报道了 一种以吡啶-3,5-二腈为电子受体, 咔唑为电子给体的蓝 光 TADF 分子 61. 通过巧妙设计, 氧基与咔唑基团分别 位于吡啶的对位位置, 使该分子既有较大的空间阻碍作 用以获得较小的 $\Delta E_{\mathrm{ST}}$ 值 $(0.04 \mathrm{eV})$, 又存在良好的分子内 电子转移, 以获得较高的 PLQY (49.7\%). 甲苯溶液中 
61 的发光波长为 $474 \mathrm{~nm}$, 获得的即时苂光和延迟苂光 寿命分别为 $9.7 \mathrm{~ns}$ 以及 $46.6 \mathrm{~ms}$. 该团队研究了分子 61 掺杂不同主体材料中的 OLED 器件, 最后获得最大 EQE 为 $21.2 \%$ 的 OLED 器件, 其最大电流效率为 $47.7 \mathrm{~cd} \cdot \mathrm{A}^{-1}$, 最大电源效率为 $42.8 \mathrm{~lm} \cdot \mathrm{W}^{-1}$, CIE 色坐标为 $(0.20,0.35)$, 为已报道的性能最优异的蓝光器件之一.

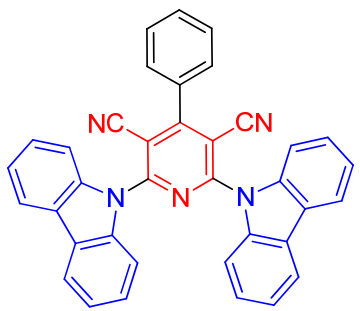

61

2016 年, $\mathrm{Wu}$ 等 ${ }^{[64]}$ 报道了一系列以㲵基吡啶, 氰基 嘧啶和氰基苯作为电子受体，9,9-二甲基鲐啶作为电子 给体的色光可调节 TADF 分子 $62 \sim 68$. 通过改变不同的 电子受体基团以及电子给受体之间的位置关系, 可实现 调节分子的发光波长, 覆盖了从蓝色光到黄色光的发光 波段. 其中氰基吡啶和氰基嘧啶作为电子受体的 TADF 分子获得了高达 $90 \% \sim 100 \%$ 的超高 PLQY. 由于 HOMO 和 LUMO 能级的有效分离, 几种分子均获得了 较低的 $\Delta E_{\mathrm{ST}}$ 值, 其中 62,67 以及 68 三种分子发光波长 在 488,462 以及 $431 \mathrm{~nm}$ 发射蓝色光. 三者的 $\Delta E_{\mathrm{ST}}$ 值和 PLQY 分别为 $0.19,0.439,0.403 \mathrm{eV}$ 和 $91.6 \%, 36 \%, 15 \%$. 一系列 TADF 分子以 ITO/PEDOT:PSS $(50 \sim 70 \mathrm{~nm}) / \mathrm{TAPC}$

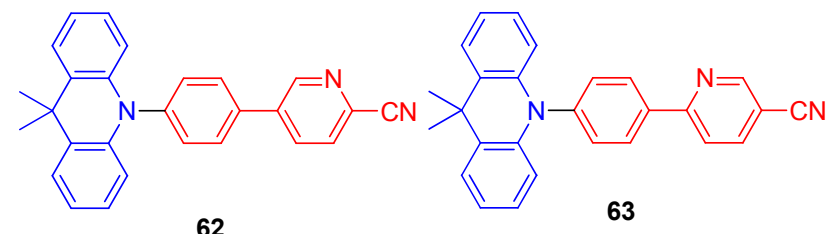

62

63

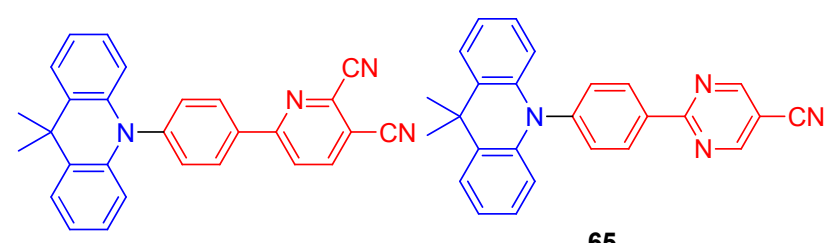

65
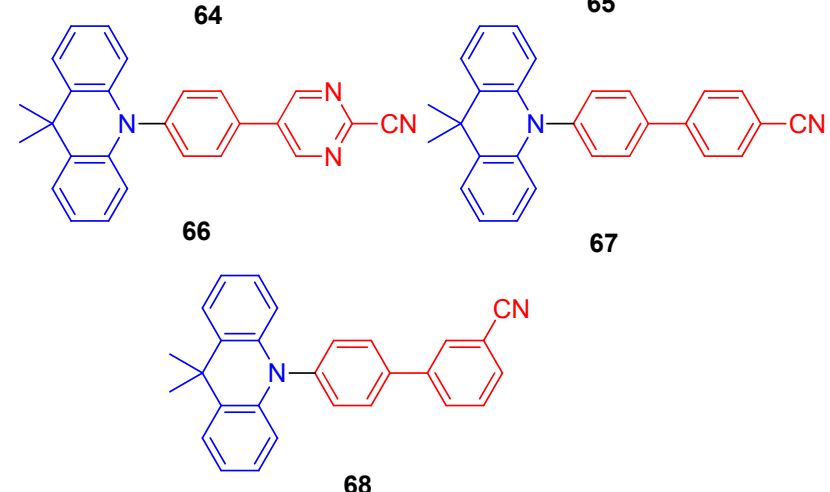

$(5 \sim 15 \mathrm{~nm}) / \mathrm{mCP}(10 \mathrm{~nm}) / \mathrm{mCPCN}: 8 \mathrm{wt} \% \mathbf{6 2} \sim \mathbf{6 8}(20 \mathrm{~nm}) /$ 3 TPYMB $(30 \sim 55 \mathrm{~nm}) / \mathrm{LiF}(0.5 \mathrm{~nm}) / \mathrm{Al}(100 \mathrm{~nm})$ 结构构成 的 OLED 器件均获得了较理想的 EQE, 三种蓝光 OLED 获得的最大 $\mathrm{EQE}$ 分别为 $23.9 \%, 5.7 \%$ 以及 $1.6 \%$. 此外，基 于 64 66 的 OLED 器件最大 EQE 高达 29.2\% 31.3\%, 为现阶段已报道的 OLED 器件中较高者.

2017 年, Lee 等 ${ }^{[65]}$ 首次报道以丙烯腈为电子受体的 蓝光 TADF 材料 69 和 70, 分别以 9,9-二甲基鲐定和 3,6二叔丁基咔唑为电子给体. 两者获得了较低的 $\Delta E_{\mathrm{ST}}$ $(0.03$ 和 $0.02 \mathrm{eV})$, 在无氧甲苯溶液中的 PLQY 为 $31.34 \%$ 和 $31.32 \%$. 基于两者的器件结构分别为 ITO $(50 \mathrm{~nm}) /$ HAT-CN (7 nm)/NPB (125 nm)/TAPC (20 nm)/mCP (10 $\mathrm{nm}) / 69(25 \mathrm{~nm}) / \mathrm{TSPO} 1(5 \mathrm{~nm}) / \mathrm{TPBi}(20 \mathrm{~nm}) / \mathrm{LiF}(2.5$ $\mathrm{nm}) / \mathrm{Al}(100 \mathrm{~nm})$ 和 ITO $(50 \mathrm{~nm}) / \mathrm{HATCN}(7 \mathrm{~nm}) / \mathrm{NPB}(40$ $\mathrm{nm}) /$ TCTA $(10 \mathrm{~nm}) / \mathbf{7 0}(20 \mathrm{~nm}) /$ Bphen $(35 \mathrm{~nm}) / \mathrm{LiF}(2.5$ $\mathrm{nm}) / \mathrm{Al}(100 \mathrm{~nm})$, 分别获得 $1.50 \%$ 和 $4.01 \%$ 的器件最大 $\mathrm{EQE}$, 发射较纯色的深蓝色和天蓝色光, CIE 色坐标分 别为 $(0.16,0.28)$ 和 $(0.15,0.14)$, 器件在 $1 \mathrm{~cd} / \mathrm{m}^{2}$ 下的启动 电压仅为 3.2 和 $3.5 \mathrm{~V}$.

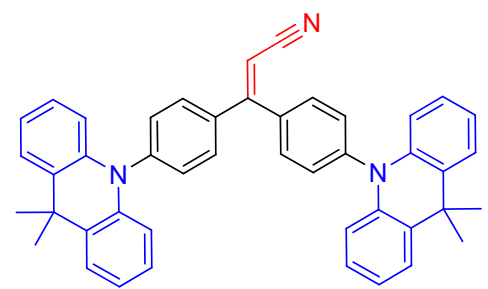

69

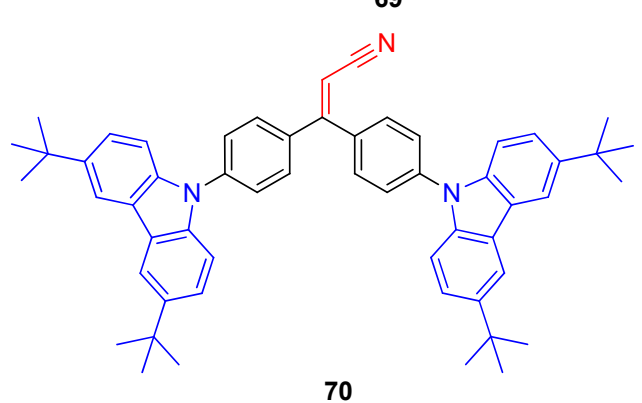

\section{4 三芳基硼类 D-A 型 TADF 蓝光材料}

硼原子由于存在空 $\mathrm{p}$ 轨道，可以用于合成三芳基衍 生物，是另一种常用于构建 D-A 型 TADF 材料的电子受 体. 2015 年, Kaji 等 ${ }^{[66]}$ 报道了一系列最大 EQE 超过 $20 \%$ 的三芳基硼衍生物 TADF 蓝光 OLED 器件. 该团队以三 均三甲苯嗍为电子受体, 分别以吩噁嗪, 二苯胺咔唑衍 生物作为电子给体合成了三种蓝光 $\mathrm{TADF}$ 分子 $71 \sim 73$. 嗍原子上连接苯环既能提供共轭平面, 甲基又能保护硼 原子免受氧气和水的破坏，使整个分子具有更好的光学 性能. 三种分子具有足够低的 $\Delta E_{\mathrm{ST}}$ 值 $(0.071,0.058$ 以及 $0.062 \mathrm{eV})$ 以实现热活性延迟苂光. 在无氧甲苯溶液中 


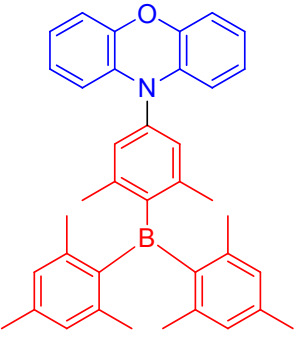

71

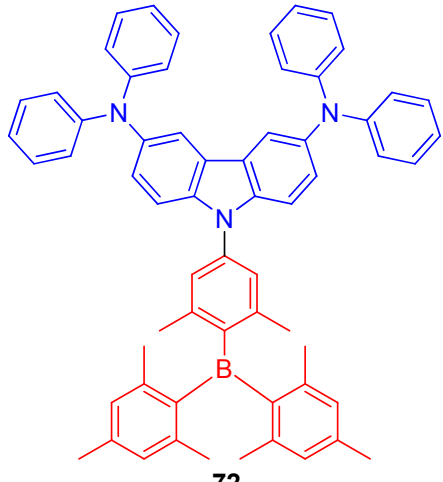

72

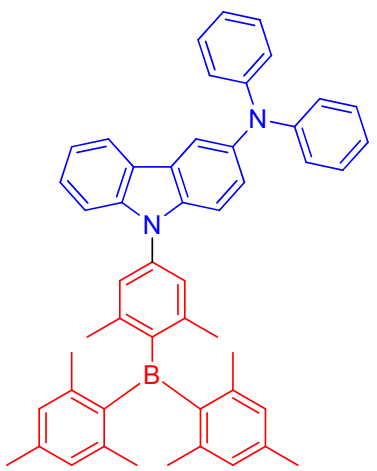

73

测试其 PLQY 分别为 44\%, 84\% 和 91\%, 发光波长分别 为 509,495 以及 $477 \mathrm{~nm}$, 发射绿色光和蓝色光. 基于 72 以及 73 两种蓝光 TADF 材料的 OLED 器件结构为: ITO $(50 \mathrm{~nm}) / \mathrm{TAPC}(80 \mathrm{~nm}) / \mathrm{PEPO}: 72$ 或 $73(16 \mathrm{wt} \%, 40 \mathrm{~nm}) /$ BAlq $(30 \mathrm{~nm}) / \mathrm{Liq}(1 \mathrm{~nm}) / \mathrm{Al}(80 \mathrm{~nm})$, 分别获得了 $21.6 \%$ 和 $14.0 \%$ 的器件最大 EQE, 两种 OLED 器件均发射天蓝 色光, CIE 色坐标分别为 $(0.18,0.43)$ 和 $(0.22,0.55)$.

由于 $10 H$-Phenoxaborin 既具有良好的吸电子能力, 又能表现出较宽的带隙以及较大的 $\pi$ 平面, 作为良好的 D-A 型的 TADF 材料电子受体, 近年来被广泛关注. 2015, Adachi 等 ${ }^{[67]}$ 以 $10 H$-Phenoxaborin 作为电子受体, 以及呋啶或咔唑衍生物作为电子给体合成了一系列高 效蓝光 $\mathrm{TADF}$ 分子 74 77. 通过引入空间体积较大的 2,4,6-三异丙基苯基，以保护中心硼原子，避免受到水 或碱以及氧气等亲核试剂的破坏, 使含嗍的衍生物基团 表现出优异的电子受体稳定性. 并且通过引入不同的电 子给体，使 TADF 分子表现出不同的性质. 例如吅啶衍 生物与周边的氢原子的空间阻碍作用, 使电子受体与 $10 \mathrm{H}$-Phenoxaborin 产生较大的二面角; 而 1,3,6,8-四甲基 咔唑的甲基在 3,6 号位的两个甲基使咔唑的电化学稳定 性更高. 4 种分子在获得 $0.06 \sim 0.12 \mathrm{eV}$ 的低 $\Delta E_{\mathrm{ST}}$ 值的同 时, 表现出 $56 \% \sim 100 \%$ 的高 PLQY, 发光波长范围从 $475 \mathrm{~nm}$ (浅蓝色光)到 $443 \mathrm{~nm}$ (深蓝色). 基于结构为 ITO $(100 \mathrm{~nm}) / \mathrm{HATCN}(10 \mathrm{~nm}) / \alpha-\mathrm{NPD}(40 \mathrm{~nm}) / \mathrm{CCP}(10 \mathrm{~nm}) /$
PPF:74 77 (50 wt\%, $20 \mathrm{~nm}) / \mathrm{PPF}(10 \mathrm{~nm}) / \mathrm{TPBi}(30 \mathrm{~nm}) /$ $\mathrm{LiF}(0.8 \mathrm{~nm}) / \mathrm{Al}(100 \mathrm{~nm})$ 的蓝光 OLED 器件分别获得超 过 $15 \%$ 的器件最大 $\mathrm{EQE}, \mathrm{CIE}$ 横纵色坐标均小于 0.16 . 其中基于 74 的 OLED 获得最高的最大 EQE (21.7\%)、 $\mathrm{CIE}$ 为 $(0.14,0.23)$ 的深蓝色光. 重要的是, 所报道的 4 种 蓝光 TADF 分子在掺杂薄膜中的 PLQY 不受掺杂浓度影 响，这在构建 OLED 器件方面具有极大优势.
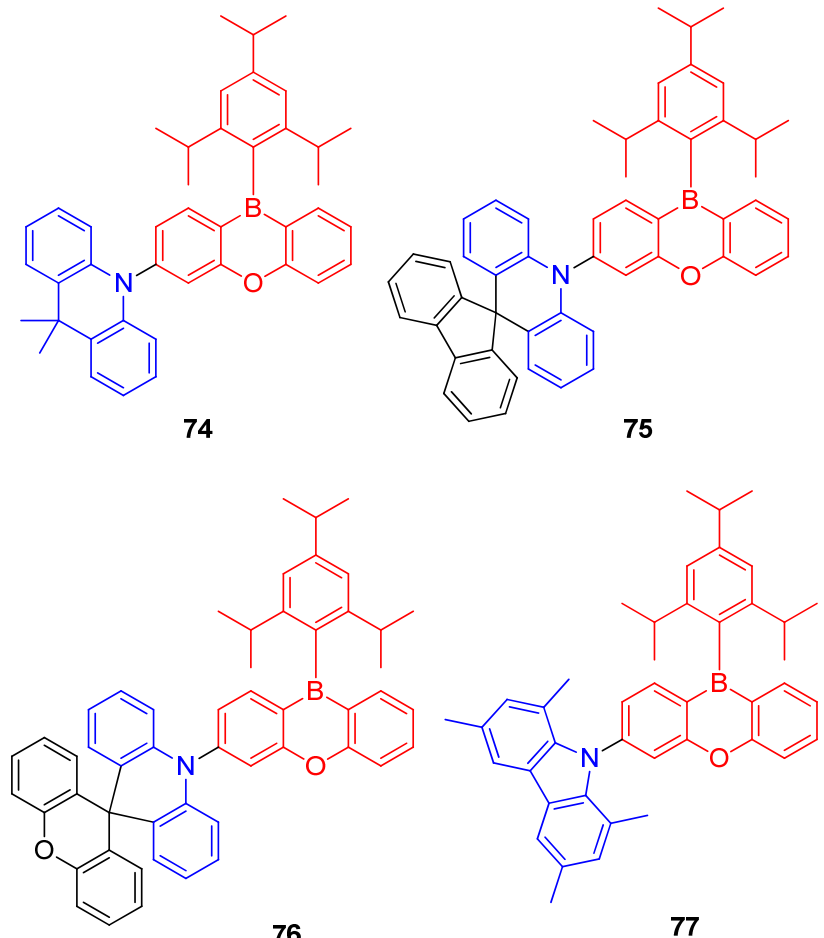

76

77

2016 年，该团队 ${ }^{[68]}$ 继续报道了一种 phenazaborin 为 电子受体, 螺呋啶为电子给体的蓝光 TADF 分子 78. 由 于分子内电子受体与电子给体之间的二面角为 $89.1^{\circ}$, 近乎相互垂直的电子给受体使分子的前线分子轨道很 大程度上分离, 使 78 获得 $0.24 \mathrm{eV}$ 的小 $\Delta E_{\mathrm{ST}}$ 值. 其掺杂 在 PPF 中制成的薄膜在氮气环境下 PLQY 达到 $99 \%$ 之 高, 发光波长在 $467 \mathrm{~nm}$ 发射蓝色光. 结构为 ITO (100 $\mathrm{nm}) / \mathrm{HAT}-\mathrm{CN}(10 \mathrm{~nm}) / \alpha$-NPD $(40 \mathrm{~nm}) / \mathrm{mCP}(10 \mathrm{~nm}) / 78$ (20 wt $\%)$ :PPF $(20 \mathrm{~nm}) / \mathrm{PPF}(10 \mathrm{~nm}) / \mathrm{TPBi}(30 \mathrm{~nm}) / \mathrm{Liq}$

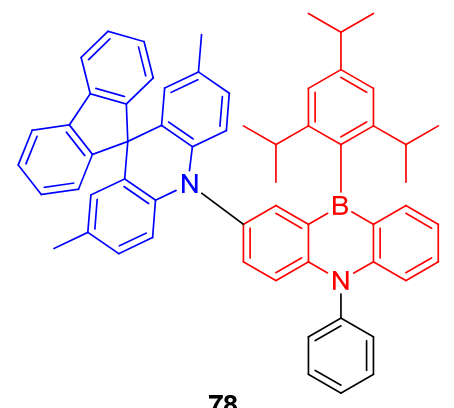

78 
$(0.8 \mathrm{~nm}) / \mathrm{Al}(80 \mathrm{~nm})$ 的 OLED 器件获得 $18.2 \%$ 的最大 $\mathrm{EQE}$, 电流效率为 $32.6 \mathrm{~cd} \cdot \mathrm{A}^{-1}$, 发光效率为 $25.6 \mathrm{~lm} \bullet$ $\mathrm{W}^{-1}$. CIE 色坐标为 $(0.15,0.23)$.

2015 年, $\mathrm{Oi}$ 等 ${ }^{[69]}$ 同样以 $10 H$-Phenoxaborin 为电子受 体, 分别以咔唑、9,9-二甲基听啶以及吩啞嗪为电子给 体合成分子 79 81. 其中 79 由于以咔唑作为电子给体 降低了咔坐与 10H-Phenoxaborin 之间的二面角, 导致分 子内 HOMO 和 LUMO 能级不能有效分离, 获得了较高 的 $\Delta E_{\mathrm{ST}}$ 值 $(0.35 \mathrm{eV})$, 未发现 TADF 现象, 仅发射蓝色的 即时苂光. 而分子 80 和 81 由于具有较低的 $\Delta E_{\mathrm{ST}}$ 值 (0.013 和 $0.028 \mathrm{eV})$, 发射浅蓝色和绿色的延迟苂光, 且 具有很高的 PLQY (98\% 和 99\%). 基于蓝光 TADF 分子 80 的器件 ITO/PEDOT:PSS (40 nm)/ $\alpha$-NPD (35 nm)/ $\mathrm{mCP}(10 \mathrm{~nm}) / \mathbf{8 0}(6 \mathrm{wt} \%)$ :DPEPO $(20 \mathrm{~nm}) / \mathrm{DPEPO}(10$ $\mathrm{nm}) / \mathrm{TPBi}(40 \mathrm{~nm}) / \mathrm{Al}(100 \mathrm{~nm})$ 获得了 $15.1 \%$ 的器件最大 EQE.

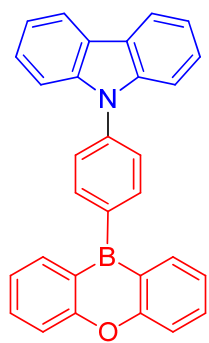

79

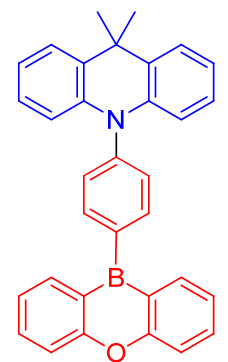

80

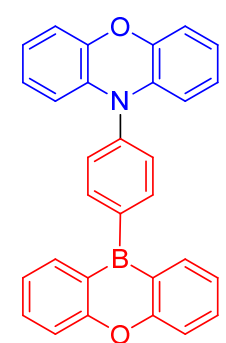

81
同年，该团队 ${ }^{[70]}$ 采取同样的设计策略，在分子 79 81 的良好光电性能基础上, 将原来 $10 H$-Phenoxaborin 电子受体改为三苯基硼合成了一系列新的 TADF 分子 82 84. 同样由于 3 种分子的电子给体与相连苯环

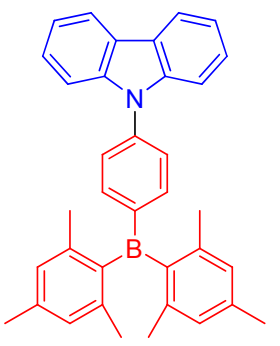

82

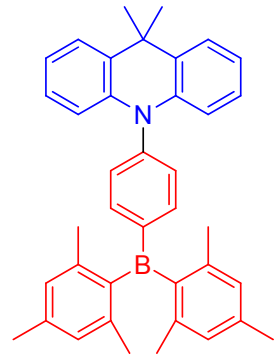

83

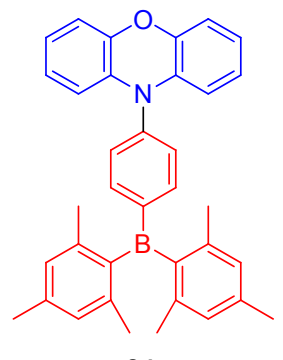

84

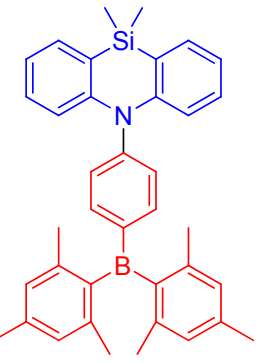

86
除 D-A 构型之外, Zhang 等 ${ }^{[20]}$ 报道了一种通过多重 共振效应有效分离 HOMO, LUMO 能级的设计策略, 获 得了超纯色的高效蓝光 TADF 材料. 通过在三苯基嗍单 元中引入氮原子, 构成刚性多环芳香框架. 而对位取代 硼原子与氮原子形成相反的共振效应，使分子共振增 强, 从而达到 HOMO 和 LUMO 能级的有效分离. 基于 独特设计的刚性 $\pi$ 共轭框架，使分子表现出较大的振子 强度, 使其 OLED 器件展现出很低的半峰宽 $(28 \mathrm{~nm})$, 从 而获得超纯色的蓝光.

\section{5 砜类 D-A 型 TADF 蓝光材料}

与二苯甲酮相似，二苯砜作为电子受体时，其在分 子中心呈现出一定的扭转角, 并且具有良好的吸电子能 力, 近年来被广泛用作电子受体构建 D-A 型 TADF 分子. 2012 年, Adachi 等 ${ }^{[72]}$ 首次以二苯砜为电子受体, 分别以 二苯胺、叔丁基二苯胺以及叔丁基咔唑合成 3 种蓝光 
TADF 分子 87 89. 通过 DFT 理论计算, 分子 87 均具 有较低的 $\Delta E_{\mathrm{ST}}$ 值 $(0.54 \mathrm{eV})$. 通过在二苯胺基团上引入叔 丁基, 以增强二苯胺单元的给电子能力, 达到了降低分 子内电子转移能量的效果, 使分子 $\mathbf{8 8}$ 获得更低的 $\Delta E_{\mathrm{ST}}$ 值 $(0.45 \mathrm{eV})$. 同样, 以咔唑单元替换二苯胺单元作为电 子给体, 增加了 ${ }^{1} \mathrm{CT}$ 态以及 ${ }^{3} \pi \pi^{*}$ 态效应, 使分子 89 获 得了 $0.32 \mathrm{eV}$ 的 $\Delta E_{\mathrm{ST}}$ 值. 3 种分子掺杂在 DPEPO 薄膜中 均发射较纯的蓝色光, 发光波长分别为 421,430 以及 $423 \mathrm{~nm}$, 并且获得 $60 \%, 66 \%$ 以及 $80 \%$ 的 PLQY. 基于 3 种蓝光 TADF 分子良好的荧光性能, 该团队以 ITO/ $\alpha$-NPD $(30 \mathrm{~nm}) /$ TCTA $(20 \mathrm{~nm}) / \mathrm{CzSi}(10 \mathrm{~nm}) / \mathrm{DPEPO}$ : 87 $\sim \mathbf{8 9}(10 \mathrm{wt} \%, 20 \mathrm{~nm}) /$ DPEPO $(10 \mathrm{~nm}) / \mathrm{TPBi}(30 \mathrm{~nm}) /$ $\mathrm{LiF}(1 \mathrm{~nm}) / \mathrm{Al}$ 为结构构造 OLED 器件. 3 种器件的最大 $\mathrm{EQE}$ 分别为 $2.9 \%, 5.6 \%$ 和 $9.9 \%$. 分子 89 发射较纯的蓝 光, CIE 色坐标为 $(0.15,0.07)$, 非常接近 NTSC 标准蓝 色. 但由于器件的发光层能带较大, 电荷能力不平衡, 导致 3 种器件表现出较为明显的效率滚降.

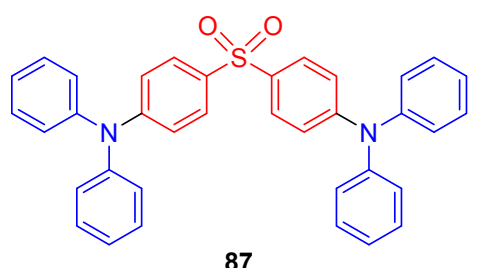

87<smiles>CC(C)(C)c1ccc(N(c2ccc(C(C)(C)C)cc2)c2ccc(S(=O)(=O)c3ccc(N(c4ccc(C(C)(C)C)cc4)c4ccc(C(C)(C)C)cc4)cc3)cc2)cc1</smiles><smiles>CC(C)(C)c1ccc2c(c1)c1cc(C(C)(C)C)ccc1n2-c1ccc(S(=O)(=O)c2ccc(-n3c4ccc(C(C)(C)C)cc4c4cc(C(C)(C)C)ccc43)cc2)cc1</smiles>

为了解决效率滚降问题，该团队 ${ }^{[73]}$ 在分子 89 的基 础上, 以富电子的甲氧基替换叔丁基, 以提高咔唑单元 的给电子能力, 合成了一种新的蓝光 TADF 分子 90. 与 分子 89 相比, 由于电子给体的给电子能力更强, 分子 90 表现出更低的 $\Delta E_{\mathrm{ST}}$ 值 $(0.24 \mathrm{eV})$. 该分子掺杂在 DPEPO 薄膜中获得与分子 $\mathbf{8 9}$ 相同的 PLQY (80\%)的同 时, 表现出更低的三重态激子跃迁时间 $(89$ 为 $270 \mathrm{~ms}, \mathbf{9 0}$
为 $93 \mathrm{~ms}) .89$ 以质量分数为 $10 \%$ 掺杂在 DPEPO 薄膜中, 制成结构为 ITO $/ \alpha$-NPD $(30 \mathrm{~nm}) / \mathrm{TCTA}(20 \mathrm{~nm}) / \mathrm{CzSi}(10$ $\mathrm{nm}) / 90(20 \mathrm{~nm}) / \mathrm{DPEPO}(10 \mathrm{~nm}) / \mathrm{TPBI}(30 \mathrm{~nm}) / \mathrm{LiF}(0.5$ $\mathrm{nm}) / \mathrm{Al}$ 的 OLED 器件获得了 $14.5 \%$ 的最大 EQE, 并表现 出较纯的蓝色光, CIE 色坐标为 $(0.16,0.16)$. 更有趣的 是，由于 90 具有很低的三重态激子跃迁时间，使其三重 态-单重态湮灭以及三重态-三重态湮灭效率大大降低, 保证基于该分子的 OLED 器件在相对高电流密度的工 作状态下仍然保持较高的外量子效率, 表现出较小的效 率滚降效应.

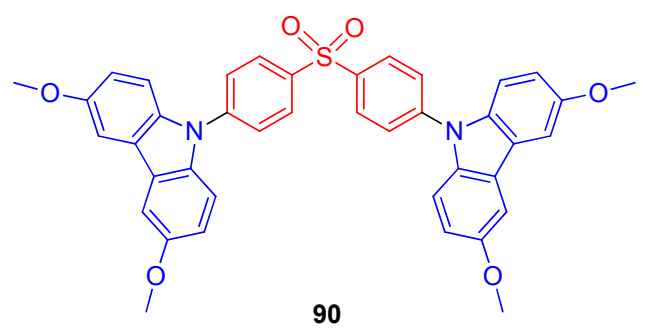

2017 年, $\mathrm{Li}$ 等 ${ }^{[74]}$ 在分子 89 的基础上, 通过引入更多 的叔丁基咔唑基团, 获得了 2 种具有更低 $\Delta E_{\mathrm{ST}}$ 值 $(0.25$ 和 $0.17 \mathrm{eV})$ 的新型的蓝光 TADF 分子 91 和 92 . 两者在普 通溶液如甲苯, 氯仿以及四氢呋喃溶液中均具有良好的 溶解性，使分子在湿法加工制作器件方面具有明显的优

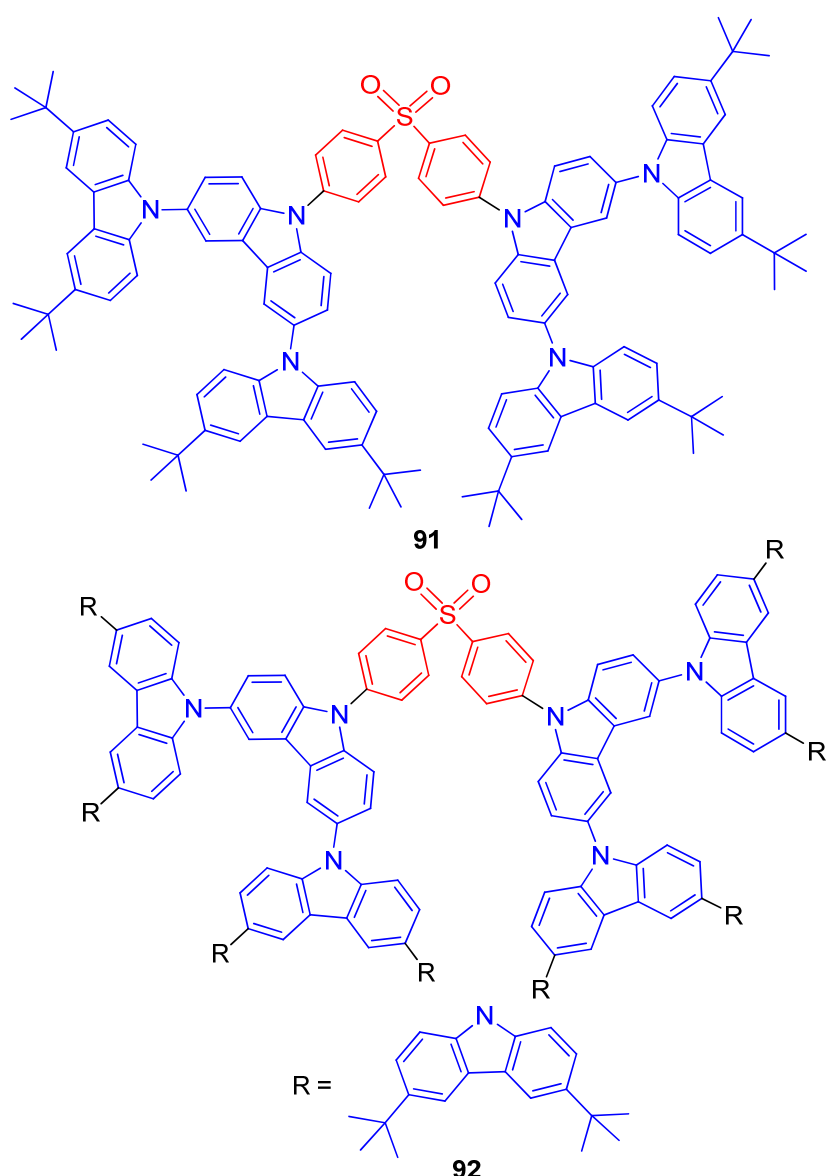


势. 在无氧的甲苯溶液中, 2 种分子分别获得了 $64 \%$ 和 $52 \%$ 的 PLQY, 最大发光波长分别在 426 和 $439 \mathrm{~nm}$, 发 射蓝色光. 基于 91 和 92, 利用湿法加工成膜制作的非 掺杂发光层器件结构为 ITO/PEDOT:PSS $(30 \mathrm{~nm}) / \mathbf{9 1}$ 或 $92(45 \mathrm{~nm}) / \mathrm{TPBI}(30 \mathrm{~nm}) / \mathrm{LiF}(1 \mathrm{~nm}) / \mathrm{Al}(100 \mathrm{~nm})$, 均能 发射较纯的蓝色光, CIE 色坐标分别为 $(0.15,0.12)$ 和 $(0.19,0.15)$, 器件启动电压均为 $5 \mathrm{~V}$ 左右 $(4.8$ 和 $5.2 \mathrm{~V})$. 基于 91 的 OLED 器件获得了较高的电流效率, 为 4.1 $\mathrm{cd} / \mathrm{A}$. 基于 92 的 OLED 器件表现出较低的效率滚降.

尽管二苯砜作为电子受体表现出良好的吸电子能 力, 并且能够与苯环连接时产生较大的扭转二面角, 以 获得较低的 $\Delta E_{\mathrm{ST}}$ 值. 但相对于其他类型的 D-A 型 TADF 分子, 近年来报道的二苯砜 TADF 分子 $\Delta E_{\mathrm{ST}}$ 值对于实现 高效热活化延迟苂光仍不理想. 所以最近研究者转向以 1,4-二(二苯砜)为电子受体合成高效的的蓝光 TADF 材 料. 例如 2015 年, Kido 的团队 ${ }^{[75]}$ 报道了两种 3,6-二叔丁 基咔唑为电子给体, 分别以 1,4-(二磺酰基苯基)苯以及 1,3-(二磺酰基苯基)苯为电子受体的蓝光 TADF 分子 93 和 94. 引入两个砜基团作为电子受体, 使 2 种分子表现 出更低的 $\Delta E_{\mathrm{ST}}$ 值, 分别为 0.19 和 $0.26 \mathrm{eV}$. 两者掺杂在 DPEPO 薄膜中显示出 56.3\% 和 69.3\% 的 PLQY. 基于上 述 2 种 TADF 分子制作结构为 ITO/NPB (30 nm)/TCTA $(20 \mathrm{~nm}) / \mathrm{CzSi}(10 \mathrm{~nm}) / 10 \mathrm{wt} \% 93$ 或 94:DTC-mBPSB: DPEPO (20 nm)/DPEPO (10 nm)/TPBI $(30 \mathrm{~nm}) / \mathrm{LiF}(1$ $\mathrm{nm}) / \mathrm{Al}$ 的 OLED 器件, 分别获得 $11.7 \%$ 和 $5.5 \%$ 的器件最 大 EQE. 其中, 93 发射深蓝色光, CIE 色坐标为 $(0.18$, $0.19)$; 而 94 则发射天蓝色光, CIE 色坐标为 $(0.15,0.08)$.

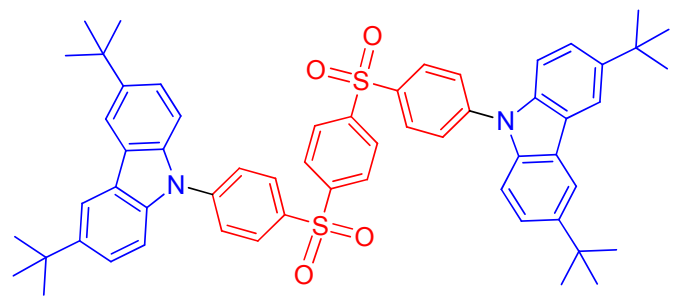

93

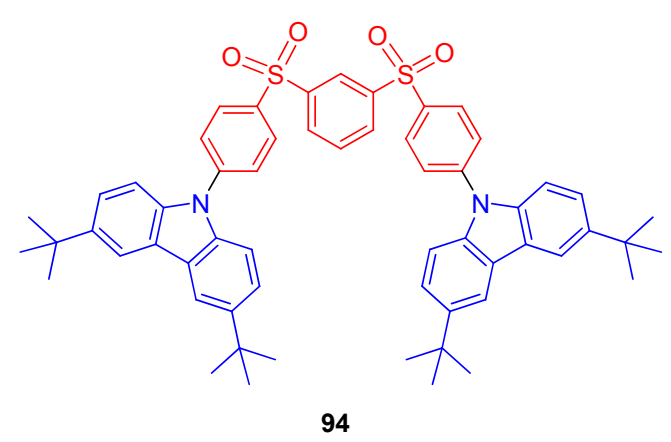

除了上述 “开环式” 的砜基电子受体蓝光 TADF 分 子外，一系列含砜基的杂环基团作为电子受体的蓝光
$\mathrm{TADF}$ 分子近年来也见诸报道. 相比二苯砜等砜基 “裸 露” 在外的电子受体基团, phenoxathiin dioxide 等含砜基 杂环电子受体, 由于杂环基团中的砜基受到更好的保 护, 表现出了更好的化学稳定性和电化学稳定性. 例如, 2016 年, Yasuda 等 ${ }^{[76]}$ 报道了一种以 phenoxathiin dioxide 为电子受体、9,9-二甲基鲐啶作为电子给体的蓝光 TADF 分子 95. 由于 phenoxathiin dioxide 的强吸电子能力以及 分子内电子给受体之间较大的空间阻碍作用, 95 获得了 $0.06 \mathrm{eV}$ 的 $\Delta E_{\mathrm{ST}}$ 值，使分子存在高效的 RISC. 所以该分 子以质量分数 $6 \%$ 掺杂在 DPEPO 主体中成膜获得了高 达 98\%的 PLQY. ITO (110 nm)/TAPC (35 nm)/ mCBP (5 $\mathrm{nm}) / \mathrm{DPEPO}: 95$ (6 wt\%, $20 \mathrm{~nm}) / \mathrm{DPEPO}(10 \mathrm{~nm}) / \mathrm{B} 3$ PyPB $(40 \mathrm{~nm}) / \mathrm{LiF}(0.8 \mathrm{~nm}) / \mathrm{Al}(80 \mathrm{~nm})$ 结构的 OLED 器件获得 了高达 $20.5 \%$ 的最大 EQE, 且发射较纯的蓝色光, CIE 色 坐标为 $(0.16,0.26)$.

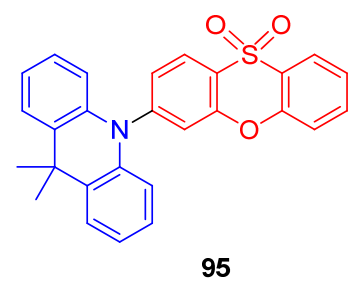

\section{3 总结与展望}

综上所述, 热活化延迟苂光材料由于具有很小的单 重态一三重态能级差 $\left(\Delta E_{\mathrm{ST}}<0.5 \mathrm{eV}\right)$, 最低激发三重态激 子可以通过吸收环境热反向系间窝越到达最低激发单 重态参与发射苂光，实现理论达到 $100 \%$ 内量子效率. 高性能的热活化延迟苂光 OLED 解决了以往传统苂光 及磷光 OLED 低效率、高造价以及性能不稳定的难题, 被誉为继苂光和磷光 OLED 后的 “第三代 OLED 器件”. 其中由于纯有机 D-A 型热活化延迟苂光分子设计可行 性高，合成方法简便，造价低廉，成为制备高光电性能 热活化延迟苂光材料分子的有效途径. 而高效的热活化 延迟苂光蓝光材料的制备，对于打破现有的技术瓶颈 (发光效率、色纯度以及稳定性问题), 实现固态发光以 及全彩显示技术的进一步发展尤为关键. 目前已报道的 热活化延迟苂光蓝光 OLED 器件中, 已经实现了最大外 量子效率高达 $30 \%$ 的同时，兼具高色纯度、长使用寿命 以及低启动电压、低效率滚降的优点. 与此同时，高效 的 TADF 材料在发光客体、敏化剂、主体等各个领域均 获得了广泛运用.

尽管如此，设计高效的 D-A 型热活化延迟菼光材料 在电子给受体和桥联基团的选择以及三者之间的键接 方式上仍需进一步系统地优化, 以获得更小 (趋近于零) 的 $\Delta E_{\mathrm{ST}}$ 值和更高的苂光量子产率和苂光寿命, 使器件 
展现出更高的最大外量子效率和使用寿命. 目前采用如 咔坐、9,9-二甲基呋啶等氮杂环电子给体的 D-A 型蓝光 热活化延迟苂光材料尽管性能出众, 但由于两类电子给 体价格相对高昂, 不利于大规模生产. 所以开发更多具 有高性价比的电子给体或电子受体亦是急待解决的问 题. 另一方面, 已报道的热活化延迟苂光材料制作成器 件时大多需要掺杂在适合的主体材料中, 以抑制其聚集 态的浓度淬灭发光和激子湮灭, 开发高效的非掺杂热活 化延迟菼光材料(如唐本忠院士开发的具有 AIE 效应的 热活化延迟苂光材料及其 OLED)既是提高器件效率的 有效途径, 亦是简化工艺和降低成本的可行之路. 同时, 开发高效的可溶性热活化延迟苂光材料以摆脱只能通 过传统的真空热蒸镀工艺加工的困境, 亦是降低制作 OLED 器件工艺成本的必要任务. 针对蓝光材料宽的 HOMO 和 LUMO 带宽 $(>3.0 \mathrm{eV})$ 不利于空穴和电子注入 有机层的固有属性, 开发更高效的蓝光材料或设计更合 理蓝光器件结构, 是实现全色显示和固态发光的更进一 步发展的突破口.

\section{References}

[1] Tang, C. W.; van Slyke, S. A. Appl. Phys. Lett. 1987, 51, 913.

[2] (a) Adachi, C. Jpn. J. Appl. Phys. 2014, 53, 101.

(b) Li, B. L. Chin. J. Org. Chem. 2015, 35, 2487 (in Chinese). (李保林, 有机化学, 2015, 35, 2487.)

(c) Wu, Y.; Zhang, Z.; Yue, S.; Huang, R.; Du, H.; Zhao, Y. Chin. J. Chem. 2015, 33, 897.

(d) Duan, L.; Tsuboi, T.; Qiu, Y. Chin. J. Chem. 2015, 33, 859.

(e) Zeng, H.; Huang, Q.; Liu, J.; Huang, Y.; Zhou, J.; Zhao, S.; Lu, Z. Chin. J. Chem. 2016, 34, 387.

(f) Jiu, Y.; Wang, J.; Liu, C.; Lai, W.; Zhao, L.; Li, X.; Jiang, Y.; Xu, W.; Zhang, X.; Huang, W. Chin. J. Chem. 2015, 33, 873.

(g) Luo, J.; Xie, G.; Gong, S.; Chen, T.; Yang, C. Chem. Commun. 2016, 52, 2292.

(f) Xie, G.; Luo, J.; Huang, M.; Chen, T.; Wu, K.; Gong, S.; Yang, C. Adv. Mater. 2017, 29, 1604223.

[3] Helfrich, W.; Schneider, W. G. Phys. Rev. Lett. 1965, 14, 229.

[4] Baldo, M. A.; O'Brien, D. F.; Thompson, M. E.; Forrest, S. R. Phys. Rev. $B$ 1999, 60, 14422 .

[5] Turro, N. J.; Ramamurthy, V.; Scaiano, J. C. Photochem. Photobiol. 2012, $88,1033$.

[6] Forrest, S. R.; Baldo, M. A.; O'Brien, D. F.; You, Y.; Shoustikov, A.; Sibley, S.; Thompson, M. E. Nature 1998, 395, 151.

[7] Tao, Y. T.; Yang, C. L.; Qin, J. Q. Chem. Soc. Rev. 2011, 40, 2943.

[8] (a) Goushi, K.; Yoshida, K.; Sato, K.; Adachi, C. Nat. Photonics 2012, 6, 253.

(b) Zhu, M. Z.; Yang, C. L. Chem. Soc. Rev. 2013, 42, 4963.

(c) Reineke, S.; Baldo, M. A. Phys. Status Solidi A 2012, 209, 2341. (d) Lin, M. S.; Chi, L. C.; Chang, H. W.; Huang, Y. H.; Tien, K. C.; Chen, C. C.; Chang, C. H.; Wu, C. C.; Chaskar, A.; Chou, S. H.; Ting, H. C.; Wong, K. T.; Liu, Y. H.; Chi, Y. J. Mater. Chem. 2012, 22,870 .

[9] Endo, A.; Ogasawara, M.; Takahashi, A.; Yokoyama, D.; Kato, Y.; Adachi, C. Adv. Mater. 2009, 21, 4802.

[10] Zhang, Q.; Li, B.; Huang, S.; Nomura, H.; Tanaka, H.; Adachi, C. Nat. Photonics 2014, 8, 326.

[11] Sato, K.; Shizu, K.; Yoshimura, K.; Kawada, A.; Miyazaki, H.; Adachi, C. Phys. Rev. Lett. 2013, 110, 247401.

[12] Baleizão, C.; Nagl, S.; Borisov, S. M.; Schäferling, M.; Wolfbeis,
O. S.; Berberan-Santos, M. N. Chem.-Eur. J. 2007, 13, 3643.

[13] Tao, Y.; Yuan, K.; Chen, T.; Xu, P.; Li, H.; Chen, R.; Zheng, C.; Zhang, L.; Huang, W. Adv. Mater. 2014, 26, 7931.

[14] Chen, T.; Zheng, L.; Yuan, J.; An, Z.; Chen, R.; Tao, Y.; Li, H.; Xie, X.; Huang, W. Sci. Rep. 2015, 5, 10923.

[15] Uoyama, H.; Goushi, K.; Shizu, K.; Nomura, H.; Adachi, C. Nature 2012, 492, 234.

[16] Mehes, G.; Nomura, H.; Zhang, Q.; Nakagawa, T.; Adachi, C. Angew. Chem., Int. Ed. 2012, 51, 11311.

[17] Kawasumi, K.; Wu, T.; Zhu, T.; Chae, H. S.; Van Voorhis, T.; Baldo, M. A.; Swager, T. M. J. Am. Chem. Soc. 2015, 137, 11908.

[18] Lee, S. Y.; Yasuda, T.; Yang, Y. S.; Zhang, Q.; Adachi, C. Angew. Chem. 2014, 126, 6520.

[19] Lee, S. Y.; Yasuda, T.; Park, I. S.; Adachi, C. Dalton. Trans. 2015, $44,8356$.

[20] Zhang, Q.; Li, J.; Shizu, K.; Huang, S.; Hirata, S.; Miyazaki, H.; Adachi, C. J. Am. Chem. Soc. 2012, 134, 14706.

[21] Yao, L.; Yang, B.; Ma, Y. Sci. China, Chem. 2014, 57, 335.

[22] Guo, J.; Li, X. L.; Nie, H.; Luo, W.; Gan, S.; Hu, S.; Hu, R.; Qin, A.; Zhao, Z.; Su, S. J.; Tang, B. Z. Adv. Funct. Mater. 2017, 27, 1606458 .

[23] Shizu, K.; Noda, H.; Tanaka, H.; Taneda, M.; Uejima, M.; Sato, T.; Tanaka, K.; Kaji, H.; Adachi, C. J. Phys. Chem. C 2015, 119, 26283.

[24] Hirata, S.; Sakai, Y.; Masui, K.; Tanaka, H.; Lee, S. Y.; Nomura, H.; Nakamura, N.; Yasumatsu, M.; Nakanotani, H.; Zhang, Q.; Shizu, K.; Miyazaki, H.; Adachi, C. Nat. Mater. 2015, 14, 330.

[25] Su, S. J.; Gonmori, E.; Sasabe, H.; Kido, J. Adv. Mater. 2008, 20 , 4189.

[26] Endo, A.; Sato, K.; Yoshimura, K.; Kai, T.; Kawada, A.; Miyazaki, H.; Adachi, C. Appl. Phys. Lett. 2011, $98,083302$.

[27] Hirata, S.; Sakai, Y.; Masui, K.; Tanaka, H.; Lee, S. Y.; Nomura, H.; Nakamura, N.; Yasumatsu, M.; Nakanotani, H.; Zhang, Q.; Shizu, K.; Miyazaki, H.; Adachi, C. Nat. Mater. 2015, 14, 330.

[28] Lee, S. Y.; Yasuda, T.; Nomura, H.; Adachi, C. Appl. Phys. Lett. 2012, 101, 093306.

[29] Cha, J. R.; Lee, C. W.; Lee, J. Y.; Gong, M. S. Dyes Pigm. 2016 $134,562$.

[30] Kim, H. M.; Choi, J. M.; Lee, J. Y. RSC Adv. 2016, 6, 64133.

[31] Lee, D. R.; Choi, J. M.; Lee, C. W.; Lee, J. Y. ACS Appl. Mater. Interfaces 2016, 8, 23190.

[32] Kulkarni, A. P.; Tonzola, C. J.; Babel, A.; Jenekhe, S. A. Chem. Mater. 2004, 16, 4556.

[33] Zhu, R.; Wen, G. A.; Feng, J. C.; Chen, R. F.; Zhao, L.; Yao, H. P.; Fan, Q. L.; Wei, W.; Peng, B.; Huang, W. Macromol. Rapid Commun. 2005, 26, 1729 .

[34] Zhang, Z. M.; Li, G. W.; Ma, Y. G.; Wu, F.; Tian, W. J.; Shen, J. C.; Chin. J. Org. Chem. 2000, 20, 529 (in Chinese). (张志明, 李国文, 马於光, 无房, 田文晶, 沈家骢, 有机化学, 2000, 20, 529.)

[35] Lee, J.; Shizu, K.; Tanaka, H.; Nomura, H.; Yasuda, T.; Adachi, C. J. Mater. Chem. C 2013, 1, 4599.

[36] Zhang, Q.; Li, B.; Huang, S.; Nomura, H.; Tanaka, H.; Adachi, C. Nat. Photonics 2014, 8, 326.

[37] (a) Obolda, A.; Peng, Q.; He, C.; Zhang, T.; Ren, J.; Ma, H.; Shuai, Z.; Li, F. Adv. Mater. 2016, $28,4740$.

(b) Tanaka, H.; Shizu, K.; Miyazaki, H.; Adachi, C. Chem. Commun. 2012, 48, 11392.

(c) Wu, K.; Zhang, T.; Zhan, L.; Zhong, C.; Gong, S.; Jiang, N.; Lu, Z.-H.; Yang, C. Chem.-Eur. J. 2016, 22, 10860.

(d) Takahashi, T.; Shizu, K.; Yasuda, T.; Togashi, K.; Adachi, C. Sci. Technol. Adv. Mater. 2014, 15, 034202.

[38] (a) Su, S. J.; Sasabe, H.; Takeda, T.; Kido, J. Chem. Mater. 2008, 20, 1691.

(b) Sun, Y.; Duan, L.; Zhang, D.; Qiao, J.; Dong, G.; Wang, L.; Qiu, Y. Adv. Funct. Mater. 2011, 21, 1881

[39] Sasabe, H.; Gonmori, E.; Chiba, T.; Li, Y. J.; Tanaka, D.; Su, S. J.; Takeda, T.; Pu, Y. J.; Nakayama, K. I.; Kido, J. Chem. Mater. 2008, 
$20,5951$.

[40] Park, I. S.; Komiyama, H.; Yasuda, T. Chem. Sci. 2017, 8, 953.

[41] Park, I. S.; Lee, J.; Yasuda, T. J. Mater. Chem. C 2016, 4, 7911

[42] Komatsu, R.; Sasabe, H.; Seino, Y.; Nakao, K.; Kido, J. J. Mater. Chem. C 2016, 4, 2274.

[43] (a) Wettach, H.; Jester, S. S.; Colsmann, A.; Lemmer, U.; Rehmann, N.; Meerholz, K.; Höger, S. Synth. Met. 2010, 160, 691.

(b) Shan, T.; Liu, Y.; Tang, X.; Bai, Q.; Gao, Y.; Gao, Z.; Li, J.; Deng, J.; Yang, B.; Lu, P.; Ma, Y. ACS Appl. Mater. Interfaces 2016. 8,28771

[44] Togashi, K.; Yasuda, T.; Adachi, C. Chem. Lett. 2013, 42, 383.

[45] Park, J. Y.; Kim, J. M.; Lee, H.; Ko, K. Y.; Yook, K. S.; Lee, J. Y.; Baek, Y. G. Thin Solid Films 2011, 519, 5917.

[46] Togashi, K.; Nomura, S.; Yokoyama, N.; Yasuda, T.; Adachi, C. J. Mater. Chem. 2012, 22, 20689.

[47] Takahashi, T.; Shizu, K.; Yasuda, T.; Togashi, K.; Adachi, C. Sci. Technol. Adv. Mater. 2014, 15, 34202.

[48] Kwon, D. Y.; Lee, G. H.; Kim, Y. S. J. Nanosci. Nanotechnol. 2015, 15,7828 .

[49] Tsai, W. L.; Huang, M. H.; Lee, W. K.; Hsu, Y. J.; Pan, K. C.; Huang, Y. H.; Ting, H. C.; Sarma, M.; Ho, Y. Y.; Hu, H. C.; Chen, C. C.; Lee, M. T.; Wong, K. T.; Wu, C. C. Chem. Commun. 2015, $51,13662$.

[50] Nasu, K.; Nakagawa, T.; Nomura, H.; Lin, C. J.; Cheng, C. H.; Tseng, M. R.; Yasuda, T.; Adachi, C. Chem. Commun. 2013, 49, 10385.

[51] Sun, J. W.; Baek, J. Y.; Kim, K. H.; Huh, J. S.; Kwon, S. K.; Kim, Y. H.; Kim, J. J. J. Mater. Chem. C 2017, 5, 1027.

[52] Rajamalli, P.; Senthilkumar, N.; Gandeepan, P.; Huang, P. Y.; Huang, M. J.; Ren, W. C. Z.; Yang, C. Y.; Chiu, M. J.; Chu, L. K.; Lin, H. W.; Cheng, C. H. J. Am. Chem. Soc. 2016, 138, 628.

[53] Rajamalli, P.; Senthilkumar, N.; Gandeepan, P.; Ren, W. C. Z.; Lin, H. W.; Cheng, C. H. J. Mater. Chem. C 2016, 4, 900.

[54] Masui, K.; Nakanotani, H.; Adachi, C. Org. Electron. 2013, 14, 2721.

[55] Sun, J. W.; Kim, K. H.; Moon, C. K.; Lee, J. H.; Kim, J. J. ACS Appl. Mater. Interfaces 2016, 8, 9806.

[56] Cho, Y. J.; Yook, K. S.; Lee, J. Y. Sci. Rep. 2015, 5, 7859.

[57] Lee, D. R.; Hwang, S. H.; Jeon, S. K.; Lee, C. W.; Lee, J. Y. Chem. Commun. 2015, 51, 8105 .
[58] Kim, M.; Jeon, S. K.; Hwang, S. H.; Lee, S. S.; Yu, E.; Lee, J. Y. Chem. Commun 2016, 52, 339.

[59] Cho, Y. J.; Chin, B. D.; Jeon, S. K.; Lee, J. Y. Adv. Funct. Mater. 2015, 25, 6786.

[60] Cho, Y. J.; Jeon, S. K.; Lee, S. S.; Yu, E.; Lee, J. Y. Chem. Mater. 2016, 28, 5400.

[61] Park, I. S.; Lee, S. Y.; Adachi, C.; Yasuda, T. Adv. Funct. Mater. 2016, 26, 1813.

[62] Chen, D. Y.; Liu, W.; Zheng, C. J.; Wang, K.; Li, F.; Tao, S. L.; Ou, X. M.; Zhang, X. H. ACS Appl. Mater. Interfaces 2016, 8, 16791.

[63] Liu, W.; Zheng, C. J.; Wang, K.; Chen, Z.; Chen, D. Y.; Li, F.; Ou, X. M.; Dong, Y. P.; Zhang, X. H. ACS Appl. Mater. Interface 2015, 7, 18930.

[64] Pan, K. C.; Li, S. W.; Ho, Y. Y.; Shiu, Y. J.; Tsai, W. L.; Jiao, M.; Lee, W. K.; Wu, C. C.; Chung, C. L.; Chatterjee, T.; Li, Y. S.; Wong, K. T.; Hu, H. C.; Chen, C. C.; Lee, M. T. Adv. Funct. Mater. 2016, 26, 7560 .

[65] Im, J. B.; Lampande, R.; Kim, G. H.; Lee, J. Y.; Kwon, J. H. J. Phys. Chem. C 2017, 121, 1305.

[66] Suzuki, K.; Kubo, S.; Shizu, K.; Fukushima, T.; Wakamiya, A.; Murata, Y.; Adachi, C.; Kaji, H. Angew. Chem. 2015, 127, 15446.

[67] Numata, M.; Yasuda, T.; Adachi, C. Chem. Commun. 2015, 51, 9443.

[68] Park, I. S.; Numata, M.; Adachi, C.; Yasuda, T. Bull. Chem. Soc. Jpn. 2016, 89, 375.

[69] Kitamoto, Y.; Namikawa, T.; Ikemizu, D.; Miyata, Y.; Suzuki, T.; Kita, H.; Sato, T.; Oi, S. J. Mater. Chem. C 2015, 3, 9122.

[70] Kitamoto, Y.; Namikawa, T.; Suzuki, T.; Miyata, Y.; Kita, H.; Sato, T.; Oi, S. Org. Electron. 2016, 34, 208.

[71] Kitamoto, Y.; Namikawa, T.; Suzuki, T.; Miyata, Y.; Kita, H.; Sato, T.; Oi, S. Tetrahedron Lett. 2016, 57, 4914.

[72] Zhang, Q.; Li, J.; Shizu, K.; Huang, S.; Hirata, S.; Miyazaki, H.; Adachi, C. J. Am. Chem. Soc. 2012, 134, 14706.

[73] Wu, S.; Aonuma, M.; Zhang, Q.; Huang, S.; Nakagawa, T.; Kuwabara, K.; Adachi, C. J. Mater. Chem. C 2014, 2, 421.

[74] Li, J.; Liao, X.; Xu, H.; Li, L.; Zhang, J.; Wang, H.; Xu, B. Dyes Pigm. 2017, 140, 79.

[75] Liu, M.; Seino, Y.; Chen, D.; Inomata, S.; Su, S. J.; Sasabe, H.; Kido, J. Chem. Commun. 2015, 51, 16353.

[76] Lee, S. Y.; Adachi, C.; Yasuda, T. Adv. Mater. 2016, 28, 4626.

(Zhao, C.) 